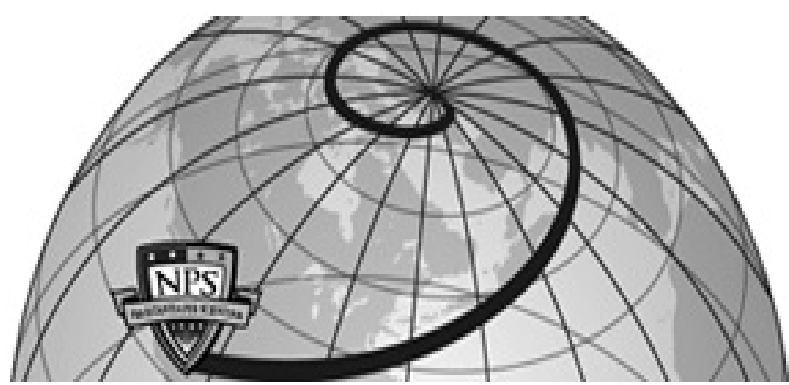

Calhoun: The NPS Institutional Archive DSpace Repository

1971-03

\title{
Analysis of temperature and velocity fluctuations in the atmospheric boundary layer
}

Gill, Thomas Edward, II

http://hdl.handle.net/10945/15578

This publication is a work of the U.S. Government as defined in Title 17, United States Code, Section 101. Copyright protection is not available for this work in the United States.

Downloaded from NPS Archive: Calhoun

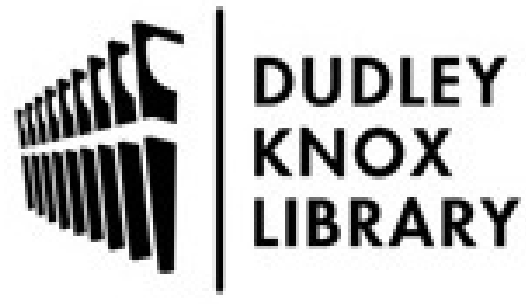

http://www.nps.edu/library
Calhoun is the Naval Postgraduate School's public access digital repository for research materials and institutional publications created by the NPS community. Calhoun is named for Professor of Mathematics Guy K. Calhoun, NPS's first appointed -- and published -- scholarly author.

Dudley Knox Library / Naval Postgraduate School 411 Dyer Road / 1 University Circle Monterey, California USA 93943 
ANALYSIS OF TEMPERATURE AND VELOCITY

FLUCTUATIONS IN THE ATMOSPHERIC BOUNDARY LAYER

by

Thomas Edward Gill 
. 


\section{United States \\ Naval Postgraduate School

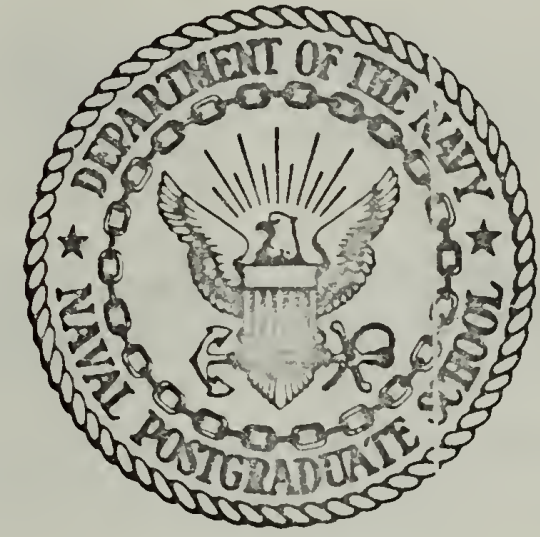

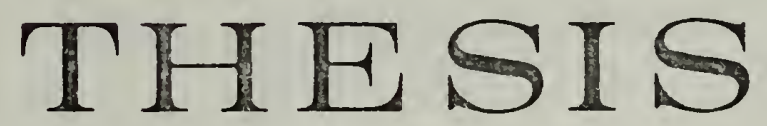

ANALYSIS OF TEMPERATURE AND VELOCITY

FLUCIUATIONS IN THE ATMOSPHERIC BOUNDARY LAYER by

Thomas Edward Gill, II

Thesis Advisor: N. E. J. Boston

March 1971

Approved for public release; distribution unlimited. 

Analysis of Temperature and Velocity

Fluctuations in the Atmospheri.c Boundary Layer

$$
\text { by }
$$

Thomas Edward Gill, II

Lieutenant Commander, United States Navy

B.S., College of the Holy Cross, 1961

Submitted in partial fulfillment of the requirements for the degree of

MASTER OF SCIENCE IN OCEANOGRAPHY

from the

NAVAL POSTGRADUATE SCHOOL

March 1971 



\section{ABSTRACT}

Measurements of high frequency temperature and velocity fluctuations were made in the atmospheric boundary layer. These data were analyzed using analog correlating techniques to obtain the structure function rather than spectral methods to obtain the spectral densities. The autocorrelation function of temperature fluctuations at 4 meters and 2 meters was computed as was the autocorrelation function of downstream velocity fluctuations at 4 meters. The cross-correlation function of temperature and downstream velocity fluctuations at 4 meters was also examined. These results supported the Kolmogorov ideas at high wave numbers. There is apparently very little correlation between downstream velocity fluctuations and temperature fluctuations. This indicates the independence of the two sensing systems and that temperature fluctuations are related primarily to vertical air movement rather than random fluctuations in the horizontal air flow. This aspect is further clarified by examining the temperature fluctuation records at two heights. 
TABLE OF CONTENTS

I. INTRODUCTION

II. DESCRIPTION OF DATA

A. FIELD SITE --_-_-_-

B. EXPERIMENTAL EQUIPMENT AND SENSORS -....-.-- 11

1. Platinum Resistance Thermometer -._-_-_-- 11

2. Hot-Wire Anemometer -.--_-_-_-_-_-_--- 1.1

3. Cup Anemometer and Quartz Thermometers ---- 3.2

4. Recording System -.-

III. THEORETICAL RELATIONS -

A. AUTOCORRELATION AND CROSS CORRELATION FUNCTIONS -- -

B. KOLMOGOROV'S POWER LAWS AND THE STRUCTURE FUNCTION --_-

IV. ANALYSIS PROCEDURES --

A. SELECTION OF DATA - -

B. CORRELATION EQUIPMENT AND PROCEDURES -------- 2.8

V. RESULTS -

A. EVIDENCE OF ORGANIZED MOTION IN THE FLOW ----- 30

B. CORRELATION ANALYSIS -

C. STRUCTURE FUNCTION

VI. CONCLUSIONS -

APPENDIX A: Digital Spectral Analysis Procedures ------- 49

BIBLIOGRAPHY -

INITIAL DISTRIBUTION LIST -

FORM DD 1473 



\section{LIST OF FIGURES}

Figure

Page

1. Location of Field Site

2. Block Diagram of Recording System

3. Data Record Selected for Analysis (Direct and Differentiated Signals) _._._. 26

4. Data Record Selected for Analysis (Direct Signals) - 27

5. Strip Chart Record of Temperature Pulses

Exhibiting Plume Properties _..._. 32

6. Schematic of Thermal Plumes in Shear Flow -...-.-- 33

7. Autocorrelation of Direct Temperature Signal at 4 Meters for Various Lag Times (Tau) _-_._._.-.- 35

8. Autocorrelation of Differentiated Temperature Signal at 4 Meters for Various Lag Times (Tau) ---- 36

9. Strip Chart and Autocorrelation for Various Lag Times (Tau) of Direct Temperature Signal at 4 Meters

10. Cross Correlation of Direct Temperature and Velocity Signals at 4 Meters for Various Lag Times (Tau)

11. Structure Function Plot of Direct Temperature Signal at 2 Meters

12. Structure Function Plot of Direct Temperature Signal at 4 Meters

13. Structure Function Plot of Direct Velocity Signal

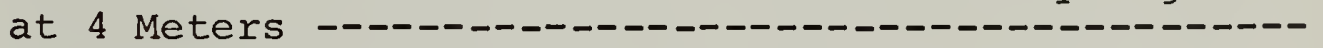

14. Structure Function Plot of Differentiated Temperature Signal at 2 Meters -----_---------

15. Structure Function Plot of Differentiated Temperature Signal at 4 Meters --_-_-_-_-_-_-_ 45

16. Structure Function Plot of Differentiated Velocity Signal at 4 Meters 



\section{ACKINOWLEDGEMENT}

The author gratefully wishes to thank his advișor, Professor Noël E. J. Boston, for providing unlimited hours of his time in helping the author over the many hurdles and hours of crises involved in this thesis. Without his enduring patience and essential advice, this work would not have reached fruition. The author is also grateful for the timely and enthusiastic assistance of Professor Kenneth L. Davidson whose encouragement and constructive ideas were most helpful.

The author's thanks also go to Professor Thomas M. Houlihan who provided the electronics necessary for analog correlation.

The author would like to acknowledge the vital technical assistance in computer programming provided by Mr. Robert L. Limes and Mr. David F. Norman of the Naval Postgraduate School staff.

Completion of this project was greatly assisted by Lt. Robert D. Jones who generously shared his time and knowledge in many areas of data processing. 



\section{INTRODUCTION}

The need to develop methods of analyzing high frequency turbulence signals is apparent. More emphasis is being given to the collection of high frequency turbulence data both in the atmosphere and in the ocean. This is partly due to the fact that technological developments have made such measurements feasible and, equally important, due to an increasing need for such data in directly estimating fundamental turbulent parameters such as energy and scalar dissipation rates.

Analysis of high frequency turbulence data presents some difficulties not encountered in low frequency analysis. Extremely large amounts of information are contained in relatively short records. In many cases this means the data must be analyzed in real time since the compression of the record by playback speed-up is not usually possible. If analog data are digitized, sampling rates must be very high which limits the length of data record that may be transferred to digital tape. High frequency turbulence signals tend to be intermittent so that areas of strong correlation, zero correlation or low correlation may be found over relatively short intervals of two signals. Furthermore, high frequency signals are small, often not much greater than system noise level.

These are some of the problems investigated in this thesis. First, how does one go about analyzing such data; and second, once analyzed how are results to be interpreted? 
Correlation and spectral analyses have found wide application in engineering and physical investigations for some time. More recently the techniques and experiences of these established sciences have been carried over into investigating geophysical phenomena. Perhaps the outstanding example in meteorology and oceanography of the application of these techniques is in micrometeorology and air-sea interaction. The correlation between temperature fluctuations and vertical velocity fluctuations leads to a direct estimate of sensible heat flux, one of the major terms in thermally-driven models of the atmosphere. The correlation between downstream and vertical velocity fluctuations leads to a direct estimate of the Reynolds stress, or momentum flux, which plays a dominant role not only in wind-generated wave theory but also in largescale wind-driven ocean circulation. Spectral analyses, combined with turbulent theories, have allowed direct estimates of the rate of turbulent kinetic energy dissipation and the rate of scalar dissipation of such quantities as temperature and humidity fluctuations. Such estimates require measurements of turbulent fluctuations to the highest possible resolution of sensors and electronics. The distribution of these quantities in space and time leads to an increase of understanding of turbulent processes. Whereas clearly the goal is the understanding of the large scale dynamics of the atmosphere and ocean, such understanding cannot be achieved until the very small processes and the non-linear ways in which they enter into large processes are understood. 
One application of studies in this field which is of special interest to the military is the possible improvement of radio communications based upon an understanding of atmospheric turbulence. Electromagnetic waves are refracted anc scattered in the atmosphere. The nature of this scattering and refraction is determined in large part by the local refractive index of air, which in turn is dependent upon both the large and small scale temperature fluctuations present. Changes in the refractive index can change the path of radio waves and seriously disrupt both long and short range radio communications. Therefore, increased understanding of temperature fluctuations and the statistics of temperature fluctuation distribution, even at very small scales, can lead to an improvement of communications by providing the necessary information to allow correct action in changing location of transmitter or receiver, changing frequency, or changing the method of propagation to suit atmospheric conditions. 


\section{DESCRIPTION OF DATA}

Based upon the desire for information concerning the distribution of temperature within a turbulent velocity field and the possible correlation in such a field between temperature and velocity fluctuations, it was decided to measure simultaneous temperature and velocity signals with instrumentation as sensitive as possible. The difficulty of accurately measuring temperature fluctuations in a velocity field led to the development of a platinum wire resistance thermometer by Boston (1970). This instrument was used to measure tem-perature fluctuations and a hot-wire anemometer was used to measure velocity fluctuations. Measurements of temperature were taken at 4 and 2 meters above the ground, and velocity was recorded at 4 meters above the ground.

\section{A. FIELD SITE}

The data examined in this study were collected at Boundary Bay, British Columbia (Figure 1). This location was the third of three sites considered. The first, Spanish Banks, British Columbia was not entirely satisfactory because temperature signals tended to be small in the stable air over the ocean. The second, Hanford, Washington, was not satisfactory because of the varied meteorological conditions encountered in air over a desert. The third, Boundary Bay, was a compromise between the first two. The air was slightly unstable as it blew across the beach off the ocean. The site is a tidal 


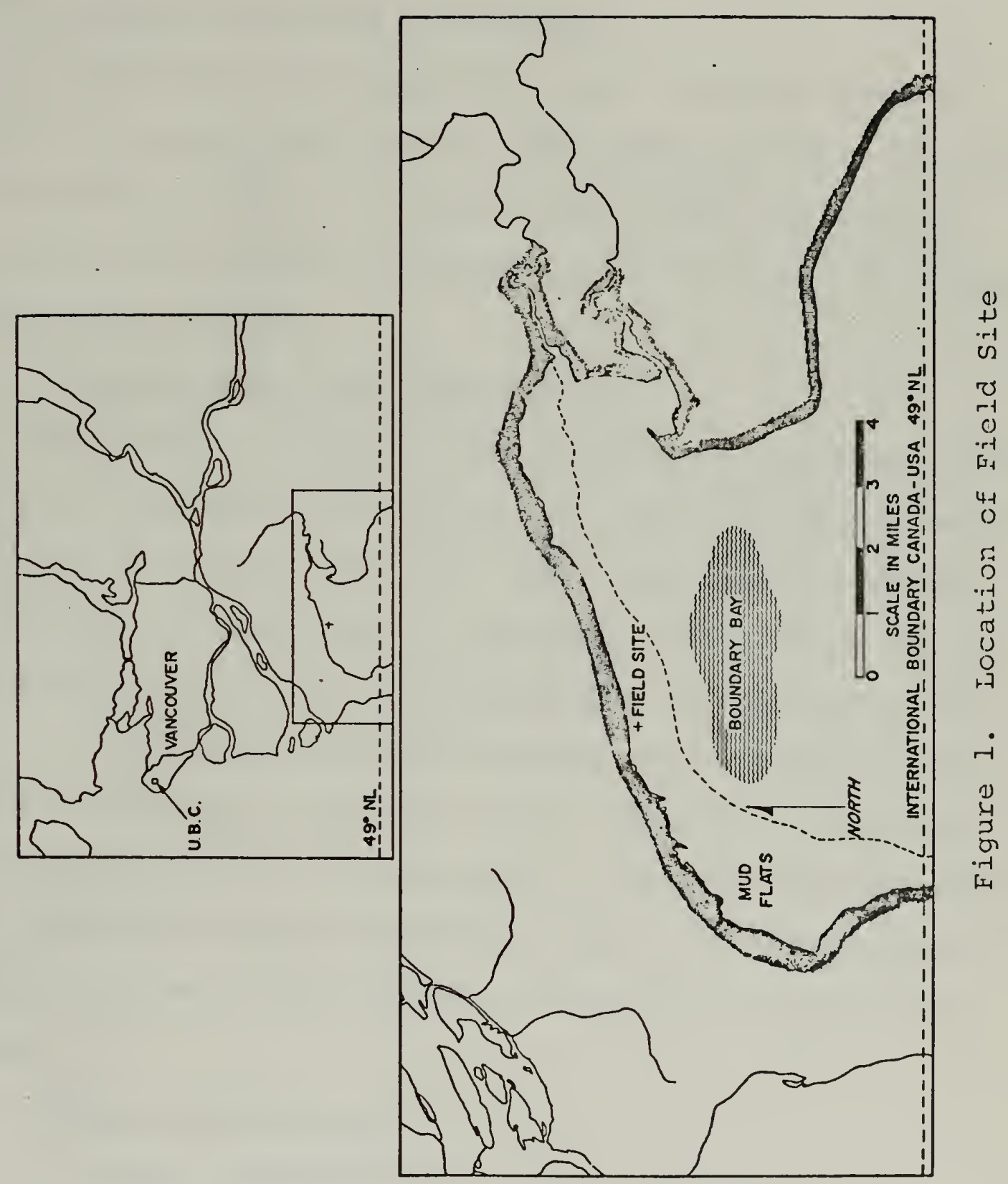



mud-flat, which is completely covered at high tide and is bare for about $2.5 \mathrm{~km}$ seaward at low tide. The site has been described in detail by Dobson (1969).

\section{B. EXPERIMENTAL EQUIPMENT AND SENSORS}

All instruments were supported from a portable mast at heights of either 4 or 2 meters. The signals from the sensors were carried by cables to a panel truck which served as the housing for the recording equipment. The truck was 30 meters downwind from the mast.

\section{Platinum Resistance Thermometer}

The sensor of temperature fluctuations was a platinum resistance thermometer consisting of a wire $0.25 \mu$ in diameter and $0.25 \mathrm{~mm}$ in length. The wire formed one leg of a wheatstone bridge. A square wave of constant amplitude is applied to the bridge via an $80 \mathrm{kHz}$ multivibrator and switching transistor. A synchronous detector is used on the bridge output. D.C. amplification is performed by an operational amplifier with fixed incremental voltage gains. Its frequency response is flat from D.C. to approximately $10 \mathrm{kHz}$. The platinum resistance thermometer electronics were placed at the foot of the mast.

\section{Hot-wire Anemometer}

A constant temperature hot-wire anemometer system (DISA model 55D05) was used. The unit was battery operated and used a $1: 1$ bridge ratio made with a compensating cable. The hot-wire probe consisted of a platinum wire $5 \mu$ in diameter and $1.0 \mathrm{~mm}$ in length. The hot-wire was mounted 
approximately $5 \mathrm{~cm}$ above the temperature sensor. Electronically this system can handle signals in the frequency range from D.C. to $100 \mathrm{kHz}$. Both the time response and wave number limitation of the wire allow signals up to $\mathrm{l} \mathrm{kHz}$ to be measured without attenuation at wind speeds of 4 to $5 \mathrm{~m} / \mathrm{sec}$.

\section{Cup Anemometer and Quartz Thermometers}

In addition to the above instruments, a cup anemometer and two quartz thermometers were used in the experimental setup. The cup anemometer, mounted on the mast at 4 meters, was used to measure mean wind speed in order to provide (1) an in-field check on the hot-wire anemometer, and (2) a mean wind speed, U $(\mathrm{cm} / \mathrm{sec})$, to apply in Taylor's hypothesis in the form

$$
\mathrm{k}=\frac{2 \pi \mathrm{E}}{\mathrm{U}}
$$

where $k$ is the radian wave number $\left(\mathrm{cm}^{-1}\right)$ and $f$ is frequency $(\mathrm{Hz})$.

The quartz thermometers were used to get an indication of the relative stability of the atmosphere. This data would be important over a 24-hour period, but not over a period as short as 8 minutes, which was the length of the recorded data used in this thesis.

\section{Recording System}

The signals from the platinum resistance thermometer and hot-wire and cup anemometers were recorded on separate FM (frequency modulated) channels of a magnetic tape recorder (Sangamo model 3562) run at 60 inches per second. The high 
frequency cut-off of the tape recorder was $20 \mathrm{kHz}$. The quartz thermometer digital meter reading was read onto the voice edge track of the tape. The recording system is outlined in Figure 2.

Since both the noise of the system and the maximum frequency of interest of the temperature signal were uncertain at the time of the experiment, recordings were made both without the low pass filter (Krohn-Hite model 3340) and with it at various settings to attenuate very high frequency noise. Data chosen to be analyzed in this thesis were recorded with a low pass filter cut-off at $10 \mathrm{kHz}$ ( $-3 \mathrm{db}$ down frequency). The signals from the platinum resistance thermometer (PRT) and the hot-wire anemometer were treated similarly. Each was recorded in two different ways chosen to optimize the incompatible requirements of noise performance and frequency response. One channel was unfiltered (L.F. GAIN) and the other was differentiated. The purpose of the differentiation circuit was to improve the signal-to-noise ratio at high frequencies so that the very small scale fluctuations could be more readily examined. L.F. GAIN provided gain not only for the direct signal but also for the signal prior to differentiation. The high frequency gain control (H.F. GAIN) determined the frequency at which there was unity gain in the differentiating circuit. H.F. GAIN was adjusted to provide optimum gain (prewhitening) of the frequencies of interest. The differentiating circuits were matched linear phase shift devices made from Philbrick P85AU operational 


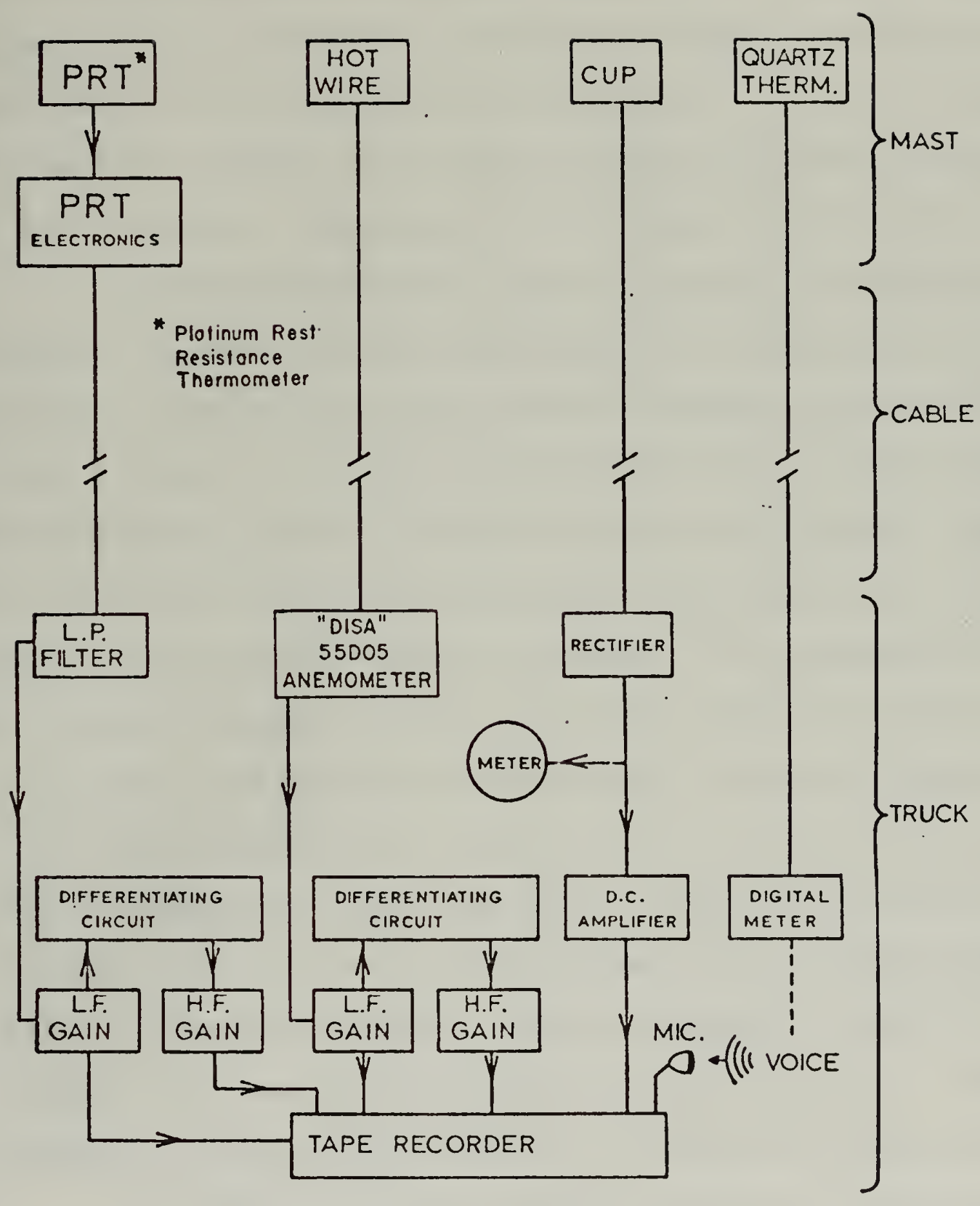

Figure 2. Block Diagram of Recording System 

amplifiers. The circuit had a 6 db/octave gain up to $10 \mathrm{kHz}$ (depending on setting) and then fell at $6 \mathrm{db} /$ octave.

Recording at 60 in/s with FM electronics ensured the best signal-to-noise ratio and provided sufficient frequency response (up to $20 \mathrm{kHz}$ ) to record faithfully the sharp rises and falls of the differentiated signals. It has the disadvantage of limiting the maximum length of a given record to 8 to 12 minutes, depending on the length of the tape.

Specifically in the case of. the data accumulated for analysis in this thesis, measurements of temperature and velocity fluctuations took place at Boundary Bay on the afternoon of August 8, 1969. Measurements were recorded on magnetic tape No. 203(1). Record length was 8 minutes commencing at 1427 PDT. A platinum resistance thermometer was located on the mast 4 meters above the ground. The temperature signal was passed through the PRT electronics where the signal was amplified, then through the Krohn-Hite low pass maximum flat filter with the cut-off frequency set at $10 \mathrm{kHz}$. The output of the Krohn-Hite filter was fed to the Philbrick amplifier manifold where both the low frequency and differentiated signals were amplified again. The low frequency, undifferentiated signal was then recorded on tape channel 5. The high frequency differentiated signal was recorded on channel 7 .

The DISA hot-wire anemometer also was located on the mast 4 meters above the ground. The velocity fluctuation signal from this sensor was fed through a Philbrick amplifier manifold for signal gain. The low frequency, undifferentiated 
signal was then recorded on tape channel 2. The high frequency, differentiated signal was recorded on channel 4. In addition, at 2 meters elevation there was another platinum resistance thermometer. The temperature fluctuation signal from this sensor was fed through and amplified by separate PRT electronics, and then passed to a Krohn-Hite low pass maximum flat filter with a cut-off frequency setting of $10 \mathrm{kHz}$. The output of the Krohn-Hite filter was then again amplified by the Philbrick amplifiers. The low frequency, undifferentiated signal was then recorded on channel 1, and the high frequency, differentiated signal on channel 3 .

In the case of all three velocity and temperature measurements, each signal was amplified by the PRT electronics and the Philbrick operational amplifiers to such a degree that complete advantage was taken of the full dynamic range of the tape recorder. 



\section{THEORETICAL RELATIONS}

Correlation analysis is a method of measuring the interdependence of variables associated with various processes, often of a random or periodic nature. Simultaneous time functions, such as turbulence data measured at a fixed point in space, can be described by correlation functions. These functions may be of the dependence of a variable at one time with itself at another time (called the autocorrelation function) or the dependence of a variable with another variable (called the cross correlation function).

\section{A. AUTOCORRELATION AND CROSS CORRELATION FUNCTIONS}

The autocorrelation function of a time series $g_{i}(t)$ at the time $t$ and $(t+\tau)$ will be indicated by $R_{i i}(\tau)$. It is obtained by averaging the products of two values separated by a lag time, $\tau$, over an observation time, $T$. The resulting average product is a function of $\tau$ : strictly

$$
\begin{aligned}
R_{i i}(\tau) & =\lim _{T \rightarrow \infty} \frac{1}{T} \int_{0}^{T} g_{i}(t) g_{i}(t+\tau) d t \\
& =\overline{g_{i}(t) g_{i}(t+\tau)} .
\end{aligned}
$$

At $\tau=0, R_{i i}(\tau)$ has its maximum value which is related to the variance of the signal by

$$
R_{i i}(0)=\overline{g_{i}(t)^{2}} \geq R_{i i}(\tau)
$$



for all $\tau$. Clearly

$$
R_{i i}(\tau)=R_{i i}(-\tau)
$$

The form of $R_{i i}(\tau)$ will be characteristic of the original signal $g_{i}(t)$.

The autocorrelation function is related to the energy spectrum $E_{i i}(f)$ (sometimes called the power spectrum) as follows:

$$
R_{i i}(\tau)=\int_{0}^{\infty} E_{i i}(f) \cdot \cos 2 \pi f \tau \cdot d f
$$

and the inverse is:

$$
E_{i i}(f)=4 \int_{0}^{\infty} R_{i i}(\tau) \cdot \cos 2 \pi f \tau \cdot d \tau,
$$

which merely states that $R_{i i}(\tau)$ and $E_{i i}(f)$ are Fourier cosine transforms of each other. One can be found from the other by integration.

The theoretical relations involved in performing cross correlation of a time series are the same as those for the autocorrelation function described here with the exception that two different signals are being correlated rather than the same signal. That is, instead of correlating $g_{i}(t)$ with itself, $g_{i}(t)$ is correlated with $g_{j}(t)$. 


\section{B. KOLMOGOROV'S POWER LAWS AND THE STRUCTURE FUNCTION}

Kolmogorov (1941) postulated that high frequency velocity fluctuations should be isotropic even though they are generated from and embedded in anisotropic eddies of low frequencies. If there is a significant region of the spectrum at high frequencies in which there is no energy feeding, then since there is an energy cascade from lower frequencies by inertial transfer, with the pressure forces tending to transfer energy among components, it would be reasonable to suppose that these smaller scales would not exhibit the anisotropy of the low wave numbers and would tend toward isotropy. This is known as local isotropy, and has been supported by experimental evidence of Batchelor (1953).

If the Reynolds numbers are high enough, turbulence will adjust through inertial transfer and viscous dissipation until a statistical steady-state, independent of the initial conditions, is obtained. This steady-state consists of energy transfer into the high frequency range that is equal to energy lost through viscous dissipation.

Kolmogorov hypothesized that at high Reynolds numbers in any turbulence, the small-scale, high frequency eddies are isotropic and in universal statistical steady-state. Their properties should depend only on the rate of dissipation of energy $(\varepsilon)$ and on the kinematic viscosity $(\nu)$, and not directly on time. Therefore motion associated with the steadystate range is uniquely determined by the parameters $\varepsilon$ and $v$. Based on dimensional analysis, Kolmogorov's conclusion 
about the form of the three-dimensional energy spectrum was

$$
\frac{E_{i i}(k)}{\left(\varepsilon v^{5}, 1 / 4\right.}=F\left(\frac{k}{k_{s}}\right)
$$

where $F$ is a universal function, $k$ is the wave number, $k_{s}$ is the Kolmogorov wave number, and $1 / \mathrm{k}_{\mathrm{s}}$ is the Kolmogorov microscale.

This has been verified quite conclusively by Grant, Stewart, and Moilliet (1962) and Pond, Stewart, and Burling (1963). From their completely separate measurements in a tidal channel and in the atmosphere, all results agreed with the above functional relation over 4.5 decades of wave numbers.

Kolmogorov's second hypothesis concerned the inertial subrange. If the Reynolds number is large enough, say, in the order of $10^{6}$, the energy-containing eddies and the dissipation wave number regions should be well separated in wave number space. There should, therefore, exist a range of wave numbers on the low wave number side of the dissipation range but at higher wave numbers than the energy-containing wave numbers in which universal statistical steady-state holds, but at which there is negligible dissipation of energy. The dominant feature would be an energy cascade by inertial forces through this inertial subrange. Since viscosity is not important in this wave number range, statistical properties are determined by the rate of dissipation only. Thus, in the inertial subrange by Kolmogorov's theory, $E_{i i}(k)$ should have the following functional relation: 



$$
E_{i i}(k)=K \varepsilon^{2 / 3} k^{-5 / 3}
$$

where $\mathrm{K}$ is the Kolmogorov constant. This equation is empirical and is obtained by dimensional analysis.

The results presented in this thesis represent structure functions of the temperature and velocity fluctuations in the atmosphere. The structure function, $D(r)$, depends on velocity or temperature differences between two points in the turbulent flow, i.e., for velocity:

$$
D_{i i}(r)=\overline{[u(x+r)-u(x)]^{2}}
$$

where $\mathrm{x}$ is a point in the turbulent field and $r$ is the separation distance.

If the turbulence is homogeneous, the structure function is related to the correlation function, $R_{i i}(r)$, by

$$
D_{i i}(r)=2\left[R_{i i}(0)-R_{i i}(r)\right] \text {. }
$$

The inverse transform relation between the correlation function and the energy spectrum, $E_{i i}(k)$, is

$$
R_{i i}(r)=\iint_{0}^{\infty} \int E_{i i}(k) \cdot \cos k r \cdot d k \text {. }
$$

The relation between the structure function and the spectrum is therefore

$$
D_{i i}(r)=2 \iint_{0}^{\infty} \int(1-\cos k r) \cdot E_{i i}(k) \cdot d k
$$

For conditions of isotropy, equation (13) reduces to (Strohbehn 1968): 


$$
D_{i i}(r)=8 \pi \int_{0}^{\infty}\left(1-\frac{\sin k r}{k r}\right) \cdot E_{i i}(k) \cdot k^{2} \cdot d k .
$$

It can be seen from equation (14) that the structure function, as the spectrum $E_{i i}(k)$, should also take on a characteristic power law behavior in isotropic turbulence. From dimensional reasoning and the assumption of dependence on $\varepsilon$ and $r$, this power law relation is

$$
D_{i \dot{i}}(r)=C \varepsilon^{2 / 3} r^{2 / 3},
$$

where $C$ is a constant of proportionality.

Similar arguments may be applied to temperature fluctuations to yield expressions for the temperature spectrum and temperature structure function with the same power law behavior. For isotropic turbulence, the temperature structure function can be related to the temperature autocorrelation function by

$$
\overline{\left(T_{1}-T_{2}\right)^{2}} \simeq \overline{2 T^{2}}\left(1-R_{i i}\right)
$$

where $\mathrm{R}_{\mathrm{i} i}$ is the autocorrelation function. Thus

$$
\left(1-R_{i i}\right) \propto r^{2 / 3} \text {. }
$$

This relation is expressed in terms of the separation distance, $r$, whereas the correlation analysis was made by varying lag time, $\tau$. Assuming homogeneity of the turbulence field, which seems entirely justified for the observations made in this study, the correlation in space should be equivalent to the correlation in time. The relation between $r$ and 

$\tau$ is

$$
\tau=\frac{r}{U}
$$

where $\tau$ is the lag time and $U$ is the mean wind speed. This is a variation of Taylor's frozen turbulence hypothesis, which is most often used to transform frequency (f) (time) spectra to wave number (k) (space) spectra:

$$
k=\frac{2 \pi f}{U} .
$$

From (18) and (19), one may relate $\tau$ to frequency since

$$
\frac{1}{\mathrm{r}} \simeq \mathrm{k} \text {. }
$$

So $f=\frac{1}{2 \pi \tau}$. 



\section{ANALYSIS PROCEDURES}

Because of the need to develop methods of analyzing high frequency turbulence signals, it was decided to use two distinct analysis procedures. An attempt was first made to perform spectral analysis on a 6-minute record of data by digital procedures. This was accomplished by means of analogto-digital conversion (XDS 9300/CI 5000 Hybrid Computer system) followed by IBM-360/67 digital computer spectral analysis. This procedure met with only limited success and is explained in Appendix A. The second procedure consisted of a correlation analysis of the analog temperature and velocity fluctuation signals by a DISA Analog Correlator. The results of this second method of analysis comprise the major results of this thesis.

\section{A. SELECTION OF DATA}

Since the objectives of this thesis were concerned with the examination of high frequency turbulence signals, it was not necessary to examine long sections of data. Thus it was decided that a record of about one minute length would be sufficient. Actually the exact record length turned out to be 50 seconds because of the scale used in recording the output of the DISA Analog Correlator.

The primary criterion for selecting a section of data for analysis was stationarity of velocity signals. In addition it was desirable that the selected section contain 

temperature fluctuations at both 4 and 2 meters elevation that could be considered typical of the 8-minute record. Therefore, with these ideas in mind, the data record selected was a 50-second section of tape $203(1)$ commencing 22 seconds after the beginning of the measurements. This section appears in Figure 3. Note that high frequency turbulence intensity of both the direct and differentiated velocity signals remains reasonably uniform over the length of this section. Figure 4 shows the direct signals only. The direct velocity signal shows that some low frequency oscillations are present, but it is not difficult to see that the velocity signal deviates very little from the mean wind speed of $3.0 \mathrm{~m} / \mathrm{sec}$.

A variety of temperature fluctuations were encountered throughout the 8-minute record. Some sections showed a signal that tended to be one-sided but with the small scale fluctuations remaining uniformly active throughout. The one-sided feature is a shape which is often characteristic of temperature signals; a gradually rising leading edge and a sharp drop-off of the trailing edge, which gives the record a sawtooth pattern. In general the signal exhibited intermittent quiet and active periods. The 50-second record selected attempted to incorporate as many of these fluctuation characteristics as possible. These characteristics will be interpreted in more detail in view of the scope and objectives of this thesis in section $V$. 


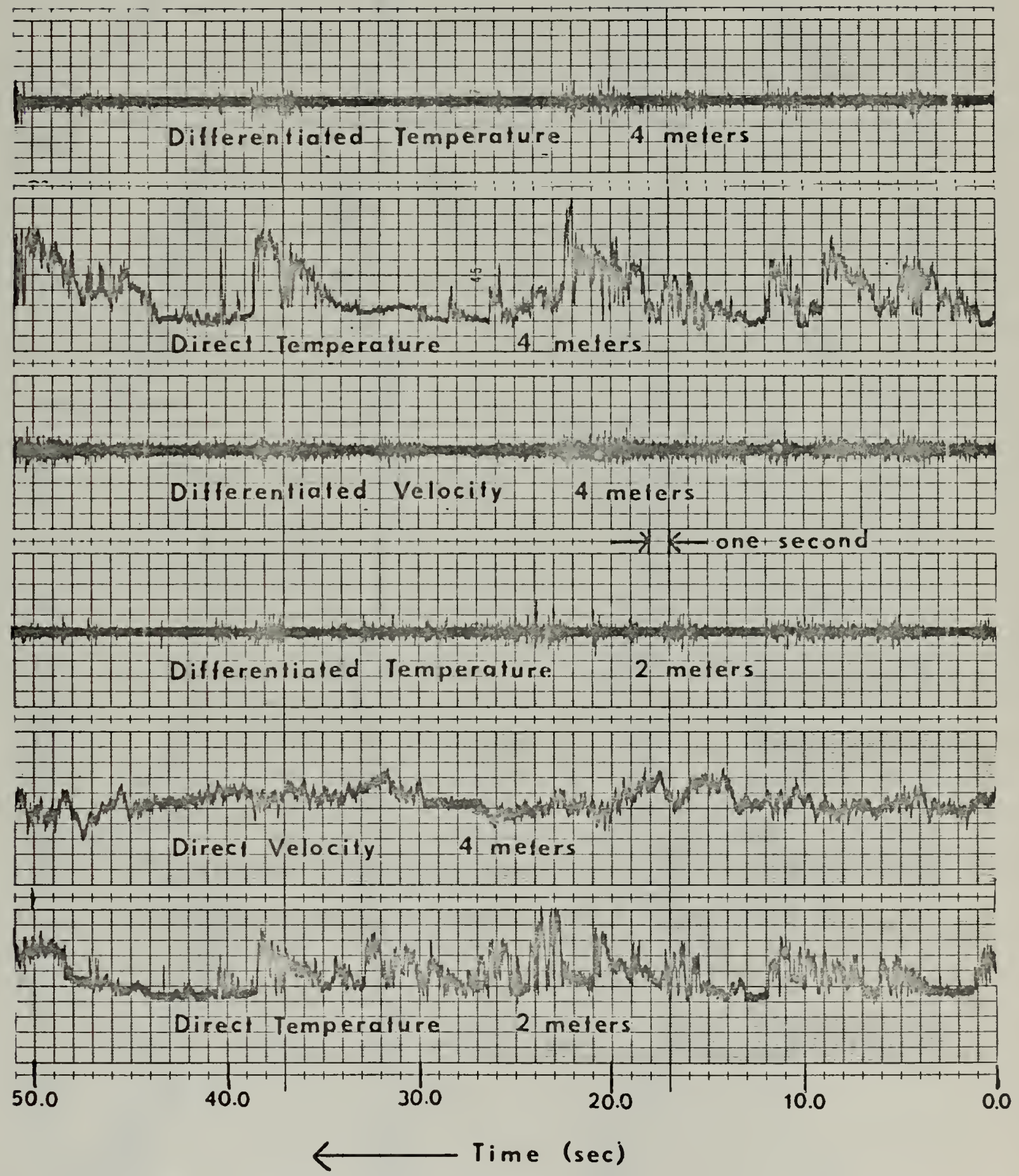

Figure 3. Data Record Selected for Analysis

(Direct and Differentiated Signals) 


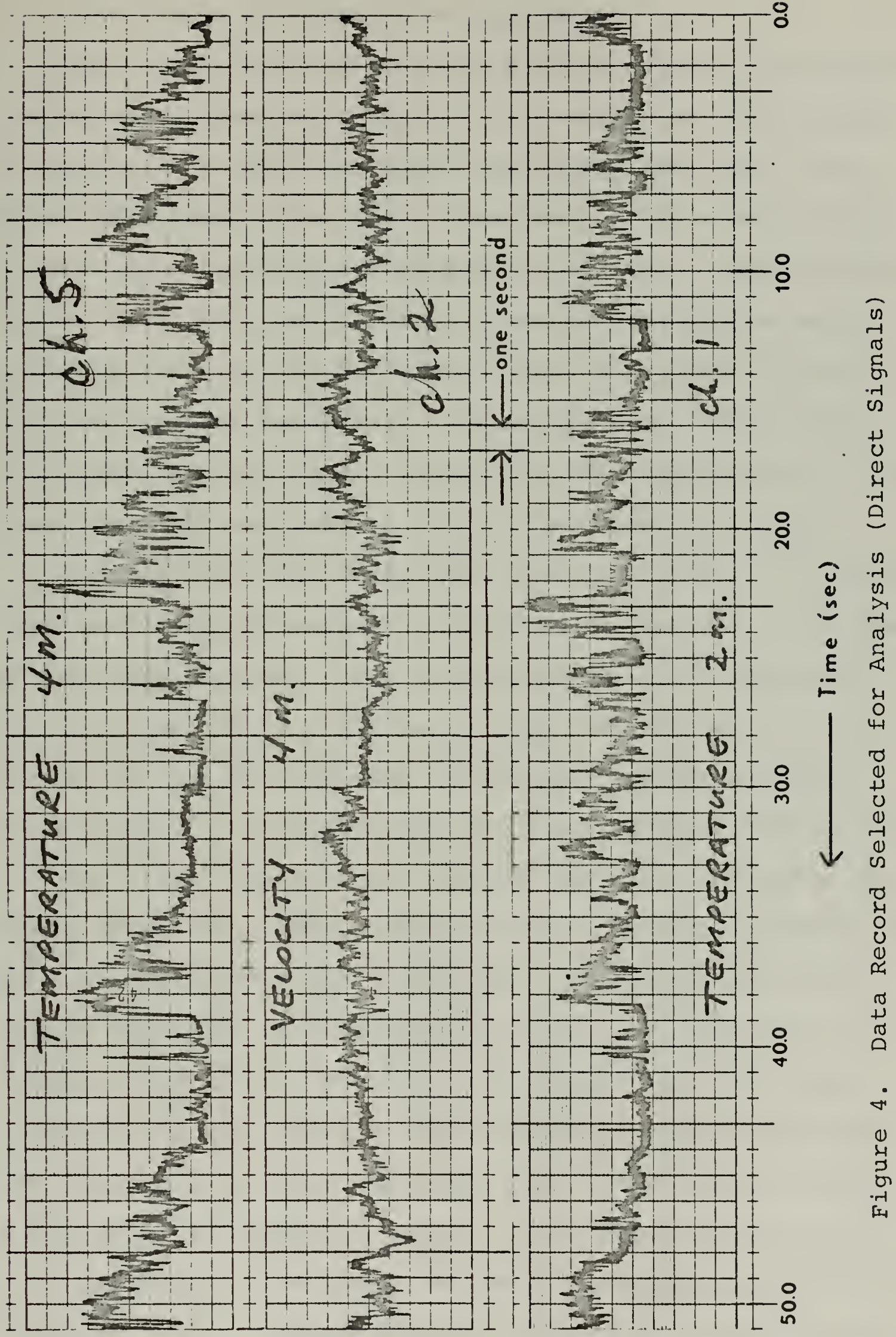



The correlation analysis was performed using a DISA Type 55D70 Analog Correlator System. In support of the DISA cor-relator were a DISA Type 55D75 Time Delay Unit and a DISA Type 52B0l Sweep Drive Unit. The sweep drive unit was used to provide a fractional breakdown of the delay range setting of the time delay unit. This feature permitted the use of convenient fractional lag times within the range of the setting on the time delay unit. In addition the sweep drive unit provided control for the Hewlett/Packard Moseley $135 \mathrm{X}-\mathrm{Y}$ Recorder which was used to record the correlator output.

The signals being correlated were reproduced on the Sangamo 3562 tape recorder and fed to the time delay unit. The speed of the tape recorder for all correlation measurements was $60 \mathrm{in} / \mathrm{s}$ (real time). The delay range setting of the time delay unit was 0-10 $\mathrm{ms}$ when correlating undifferentiated signals and 0-1 ms when autocorrelating differentiated signals. The signal was then fed through the DISA correlator and sweep drive unit. The integrating time constant setting used in all correlations was 10 seconds. This provided enough signal smoothing to recognize the large fluctuations in correlation, while also smoothing the signal of small scale fluctuations irrelevant to the fixed-lag correlation study. The lag times set into the sweep drive unit varied with the correlation of different signals. The sweep drive unit had the capability of reducing the delay range setting into fractions of 1/500. Thus different settings of lag time could 
be chosen to adequately cover the correlation range from -1.0 to 1.0. Some specific settings for selected autocorrelations are given in section $\mathrm{V}$. 



\section{RESULTS}

The results of this study are significant in light of its objectives, which were to (1) investigate methods of examining universal properties of high frequency turbulence signals and (2) to specifically examine the relation between temperature fluctuations and downstream velocity fluctuations in the atmospheric boundary layer. A visual analysis of the temperature fluctuations, especially at 4 meters elevation, provided substantial support of the work of Taylor (1958) and Priestly (1959). The correlation analysis of both direct and differentiated signals at 2 and 4 meters elevation obeyed correlation analysis theory and also agreed with Kolmogorov's $-5 / 3$ power law relation for the inertial subrange when the data were analyzed by the structure function. Finally, a lack of correlation between velocity and temperature fluctuations at the same height indicated the independence of the two sensing systems, and therefore the fact that their design is good.

\section{A. EVIDENCE OF ORGANIZED MOTION IN THE FLOW}

A consistent characteristic of the temperature data was the occurrence of "pulses" of large amplitude. These pulses occurred nearly simultaneously at both 2 and 4 meters elevation. Their occurrence was intermittent and always represented an increase in temperature. They occurred within quiescent periods during which the recorded trace appeared to have a preferred mean value. 

A selected portion of a strip chart record exhibiting these pulses appears in Figure 5. The pulses (e.g., point A in Figure 5) have a triangular shape which is distorted to give a saw-tooth pattern. Taylor (1958), Webb (1965) and Priestly (1959) have reported similar occurrences in data of these kind.

Taylor (1958) argues convincingly that the pulses are due to organized thermal structures, "plumes," embedded within the turbulent flow. Taylor reached his conclusion by performing correlation analyses between temperature fluctuations at several levels. The time lag for maximum correlations was in agreement with an expected tilt of these plumes due to the shear flow. A schematic of the plume in a shear flow appears in Figure 6.

A time lag between the occurrence of the pulse at the 2 and 4 meter level is evident at Point $A$ in Figure 5. This lag indicates that the plume was swept past the 4 meter level before the 2 meter level. Because the sensors were mounted in a plum-line arrangement, these results are in agreement with the concept that plumes, under the influence of the wind shear, are responsible for the observed pulses.

The saw-tooth characteristic of the pulses is, perhaps, due to the plumes having a well-defined trailing edge, but a leading edge that is altered by mixing or entrainment. Mixing would lower the temperature in the leading portion of the plume giving the saw-tooth pattern. 



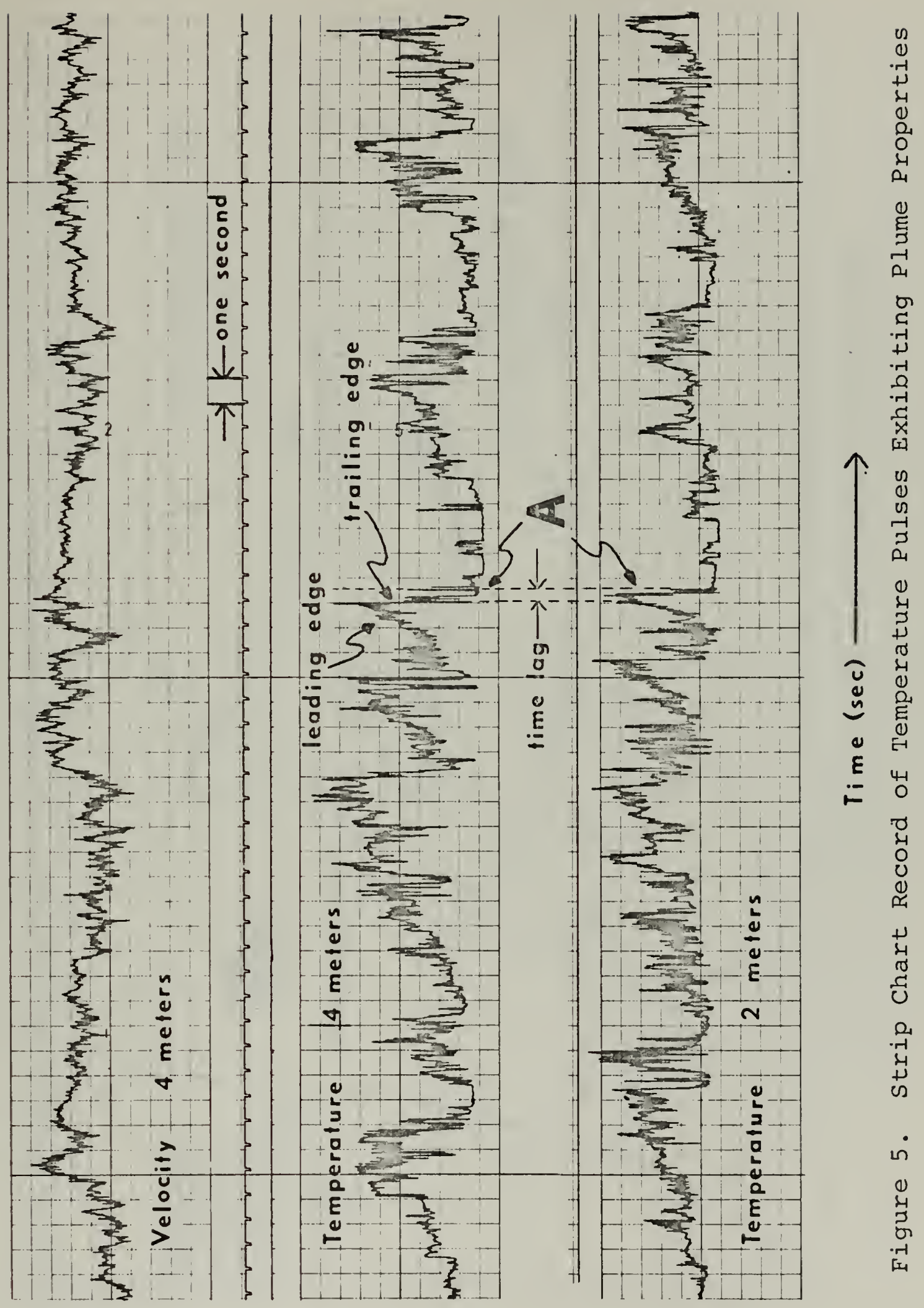




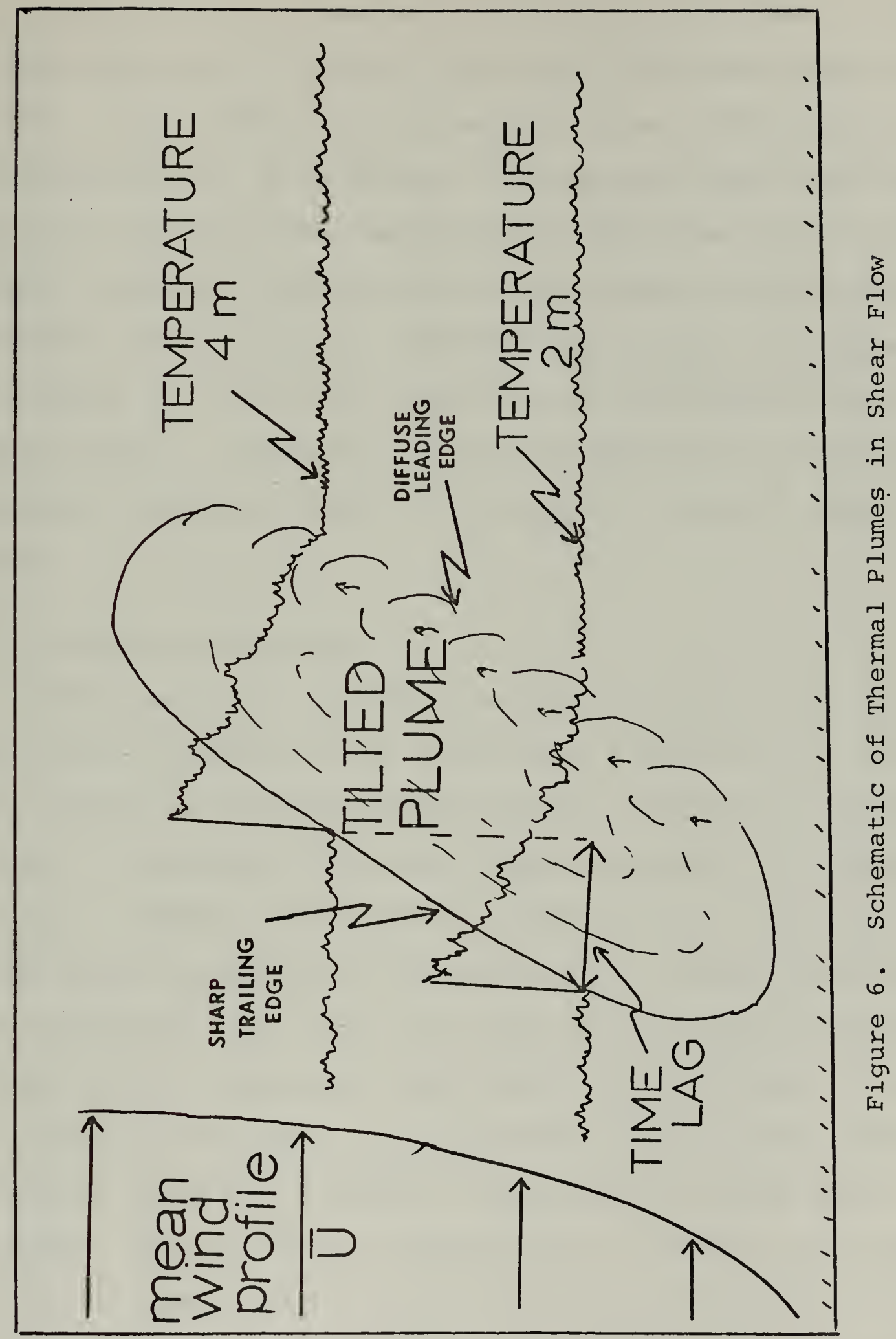


Considering the consistent occurrence of pulses in these temperature data in view of Taylor's (1958) more extensive study, it is evident that organized motion exists within the turbulent flow. By selecting a coordinate system consisting only of a trace of the temperature versus time, it is possible to obtain a description of the plumes in the complex regime. The presence of organized motion does not appear to influence the universal properties of the fluctuations at the small scales. Properties at high frequencies are examined by another coordinate system, the structure function versus time lag.

\section{B. CORRELATION ANALYSIS}

The results of the autocorrelation analysis were consistent and as expected. The correlation function, $\mathrm{R}_{\mathrm{i}}$, of both the direct and differentiated signals decreased as the lag time, $\tau$, increased. This was true throughout the 50-second record. Figure 7 is a typical example of such behavior. Here direct temperature fluctuations at 4 meters elevation are examined. Note that with $\tau$ set at $0 \mathrm{~ms}$, the autocorrelation function exhibits a high value $(\simeq .93)$ and that as the lag time is increased, $R_{i i}$ decreases in value until, with a lag time of $10 \mathrm{~ms}$, a negative correlation of mean value -.28 exists. The fact that a correlation of 1.0 does not result from a $\tau$ setting of $0 \mathrm{~ms}$ is attributed to correlation equipment calibration. When the time delay unit was set for 0 ms, in fact a slight time lag was present. 


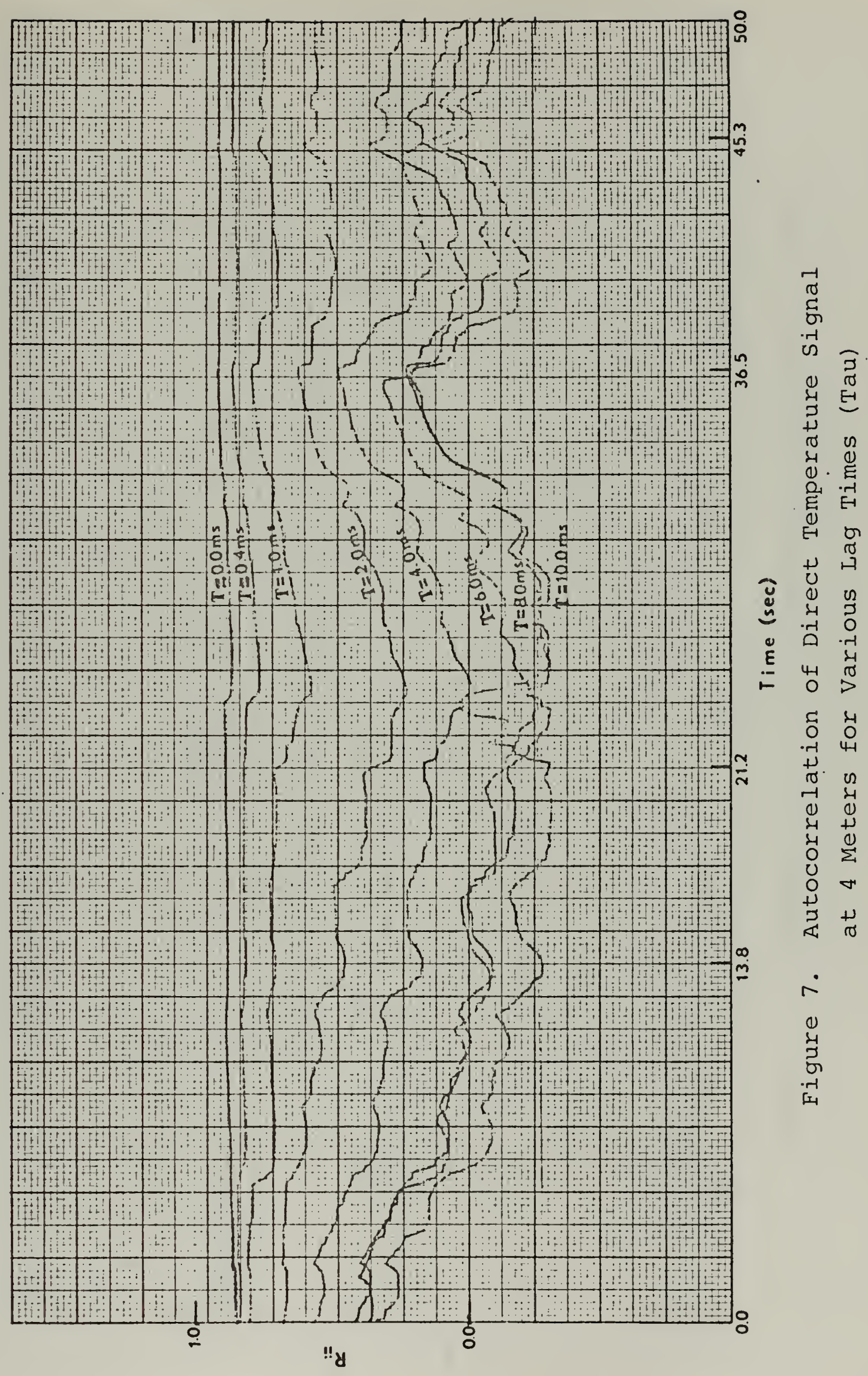





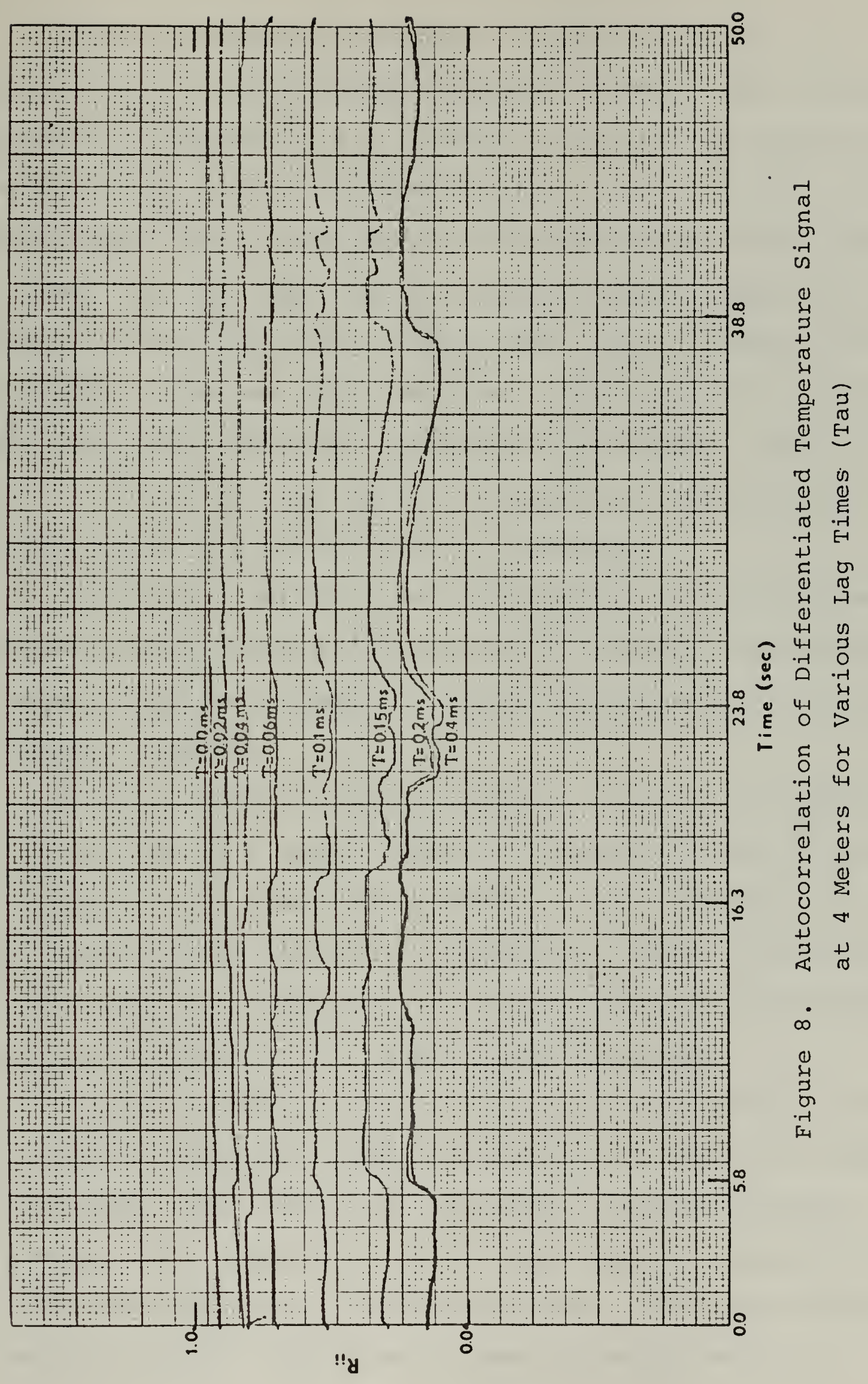



Figure 8 exhibits an example of the autocorrelation results for a differentiated signal. In this case, the dif.ferentiated temperature at 4 meters elevation was correlated with itself. Since in differentiated signals the very high frequencies (i.e., very small scale fluctuations) are accentuated, the lag times used for differentiated signals are one order of magnitude smaller than those used in correlation analysis of the non-differentiated, direct signals. However, the same autocorrelation characteristics appear. When $\tau$ is set at $0, R_{i i}$ is high, and as the lag time is increased, the value of the correlation function decreases.

In Figures 7 and 8 , a definite pattern of autocorrelation function fluctuation exists across the entire 50-second record. Times of interesting activity were selected and the structure function plotted.

Figure 9 shows the autocorrelation function of temperature fluctuations at 4 meters elevation matched with the 50-second analog trace of these same temperature fluctuations. It can be seen that the area of the temperature plume at the 36.5 second point coincides with a definite increase in correlation at the same time in the autocorrelation record.

Figure 10 shows a plot of the cross correlation of direct signals of temperature and velocity fluctuations at 4 meters elevation. The continuous low values of the correlation function, $R_{i j}$, regardless of the lag time, $\tau$, indicates that these two signals are poorly correlated. This lack of correlation between simultaneous temperature and velocity 



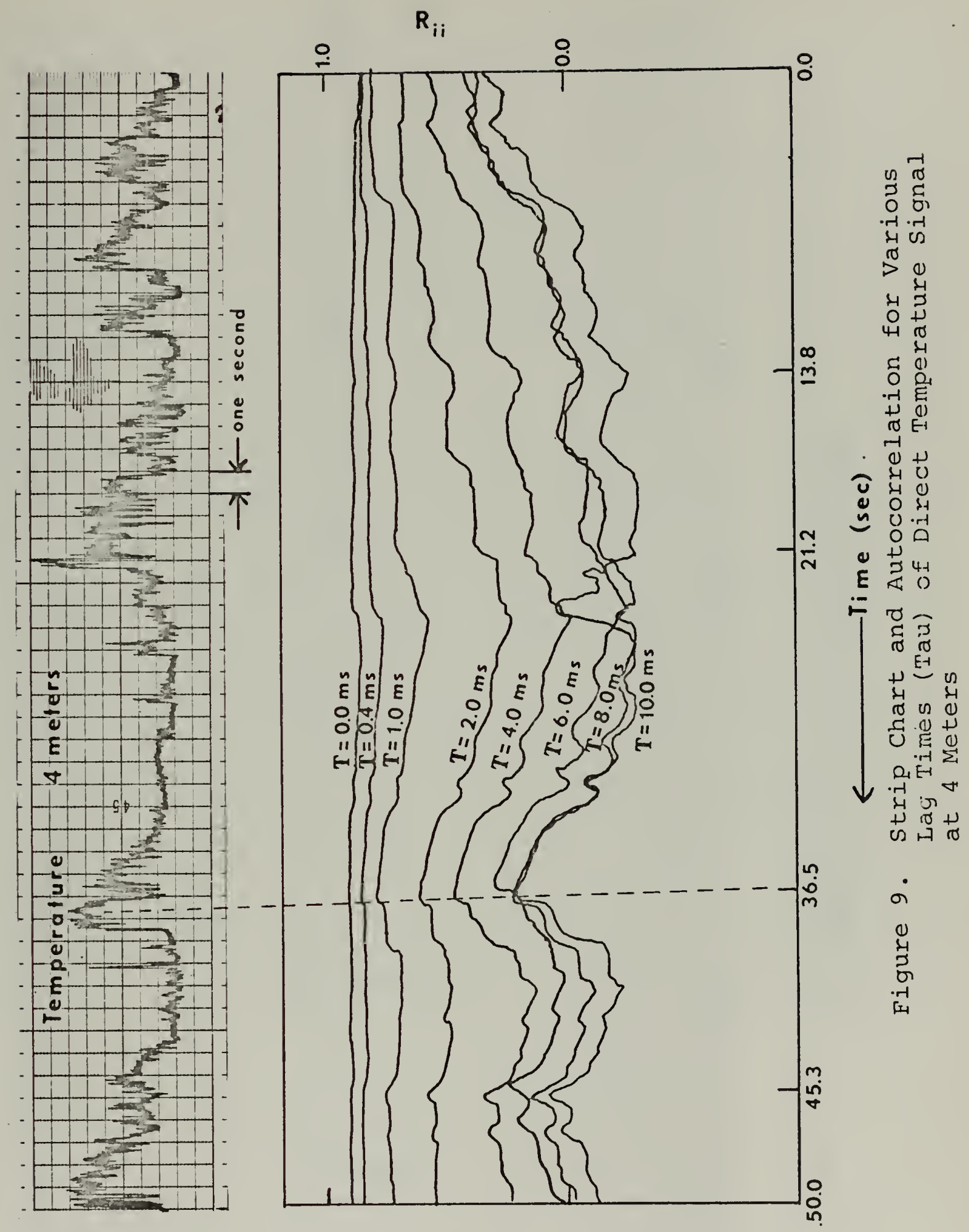





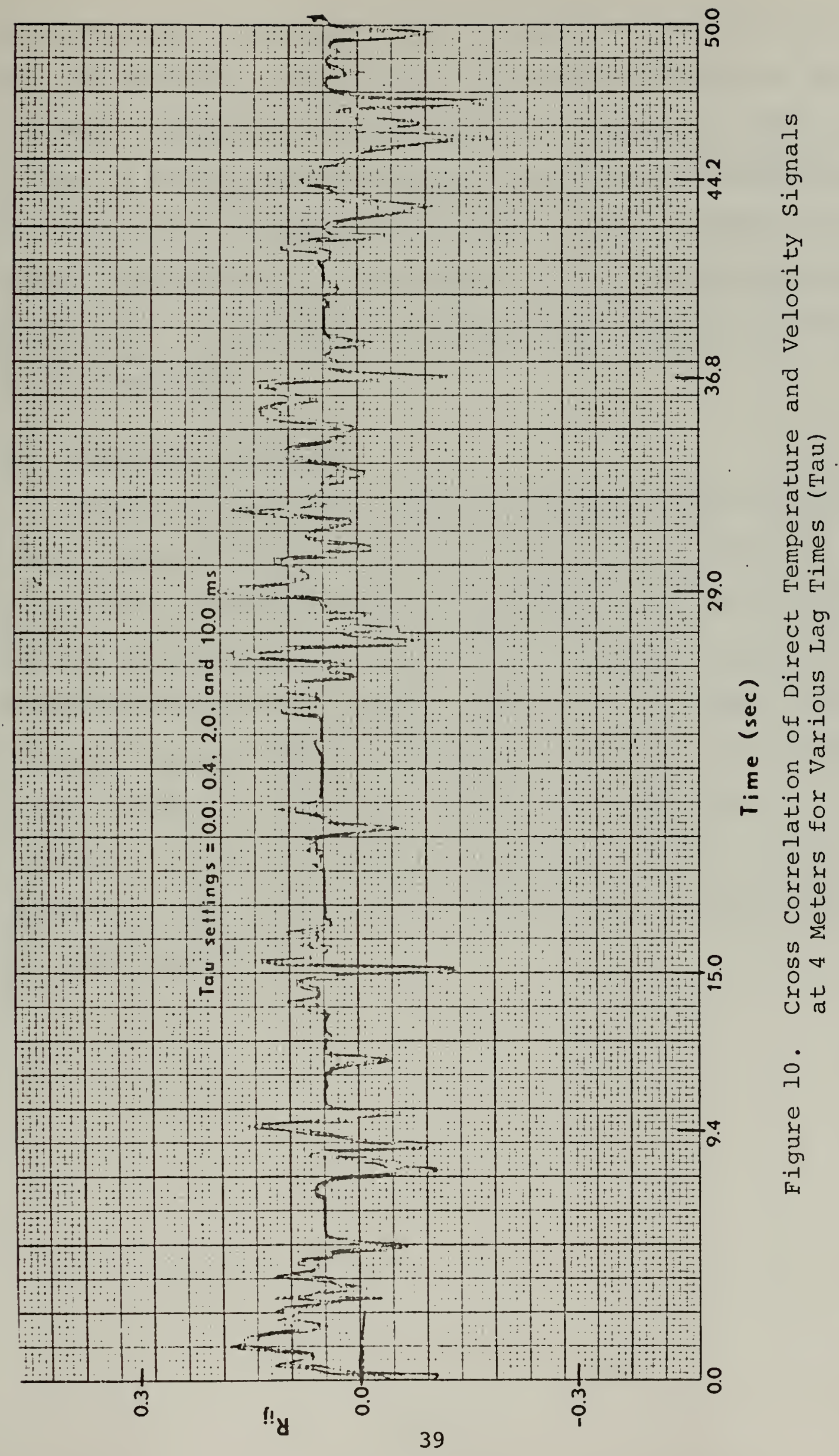



fluctuations at the same height indicates that the design of the two sensors, the platinum resistance thermometer and the hot-wire anemometer, is favorable for measuring such signals. A lack of correlation indicates that velocity fluctuations are not having a significant effect on the platinum resistance thermometer; and vice versa, that the temperature fluctuations do not affect the velocity measurements of the hotwire anemometer.

\section{STRUCTURE FUNCTION}

Figures 11 through 16 show logarithmic plots of the autocorrelation structure function, $1-R_{i i}$, versus lag time, $\tau$, for all six recorded signals at various times of interest in the 50-second record. In the cases of direct temperature fluctuations at 2 and 4 meters elevation and direct velocity fluctuations at 4 meters elevation, the slope of the plots approximates the $+2 / 3$ value predicted by applying Kolmogorov's inertial subrange hypothesis to the structure function. The slopes of the differentiated signals decrease at large values of $\tau$. 



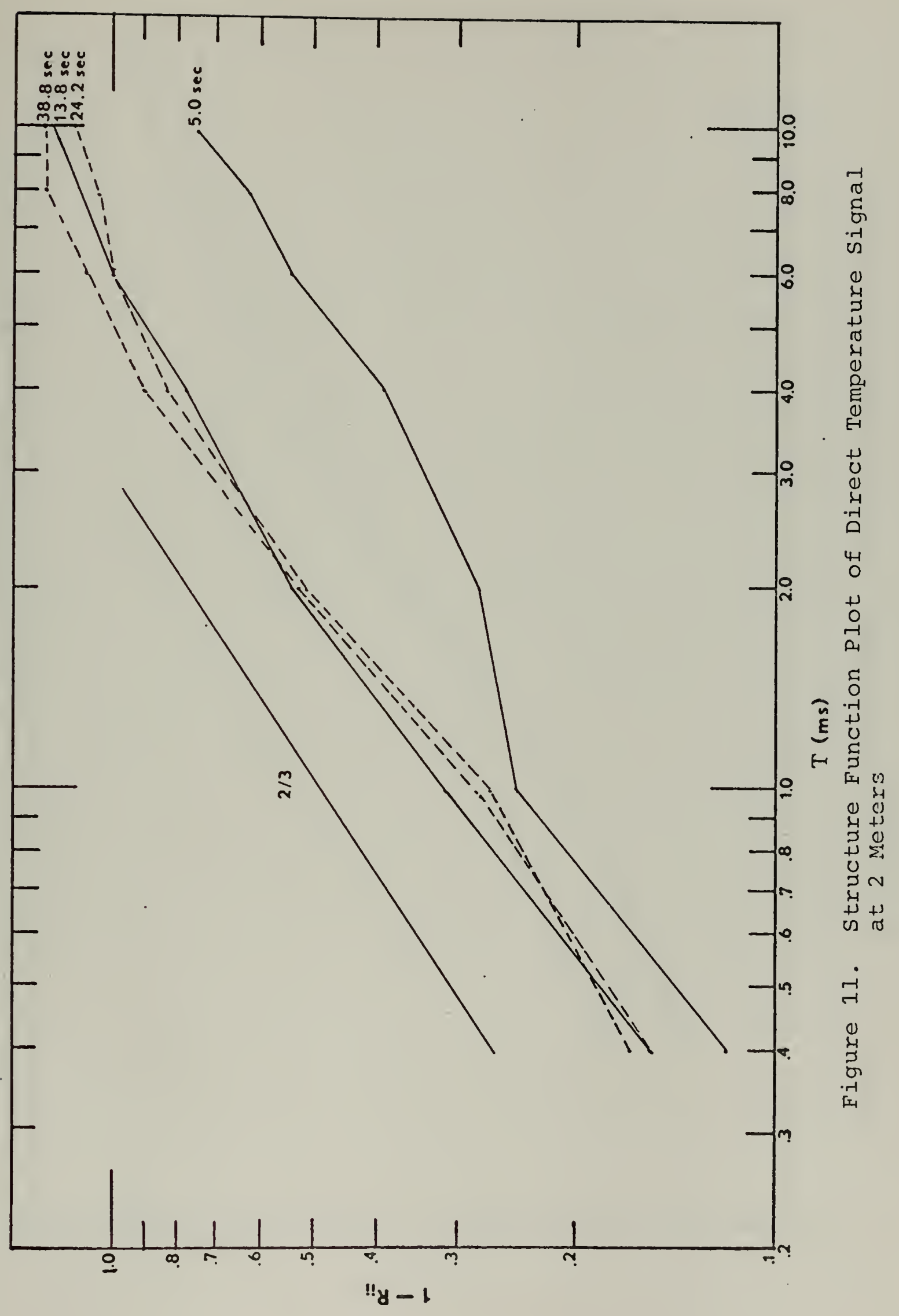





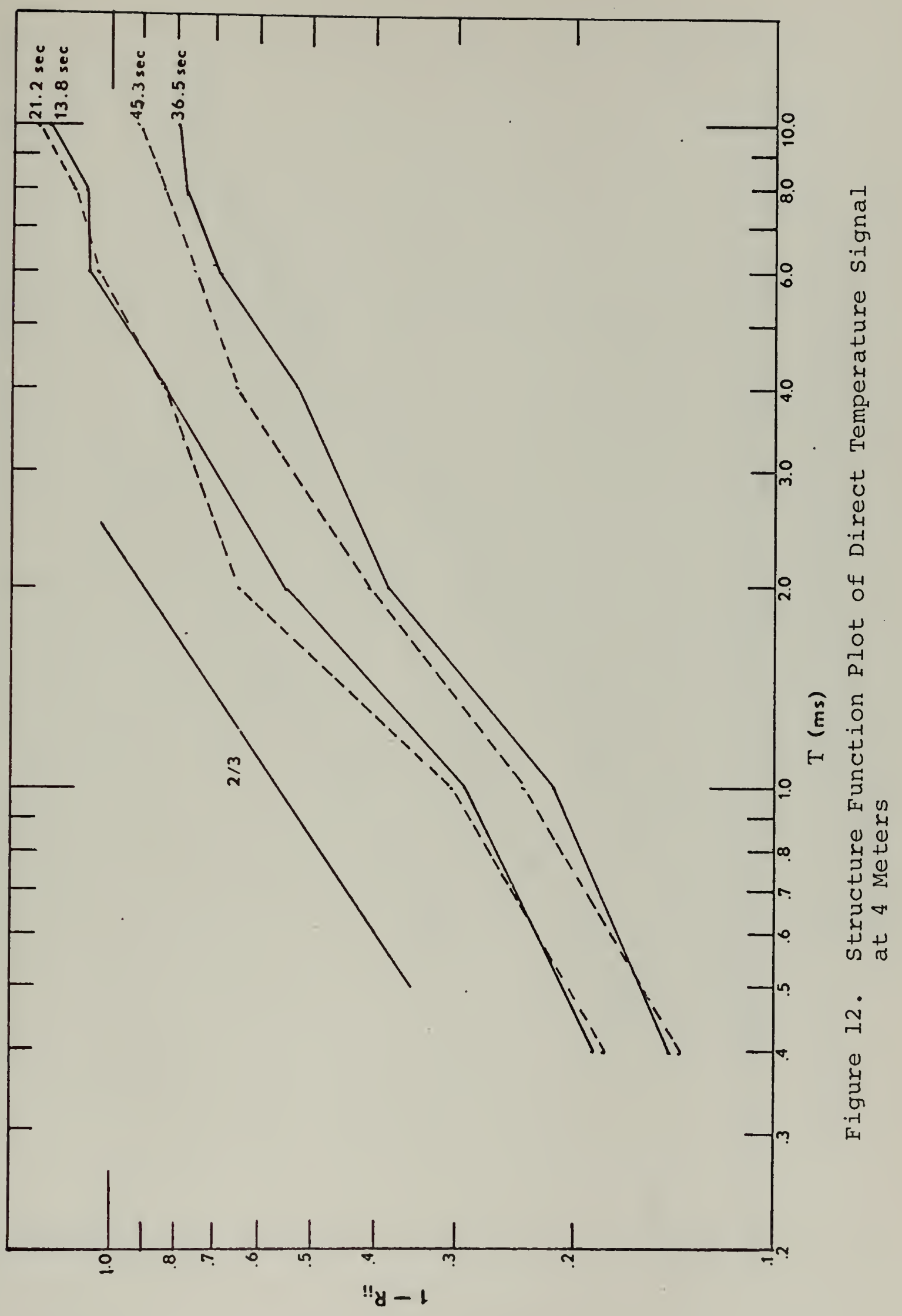





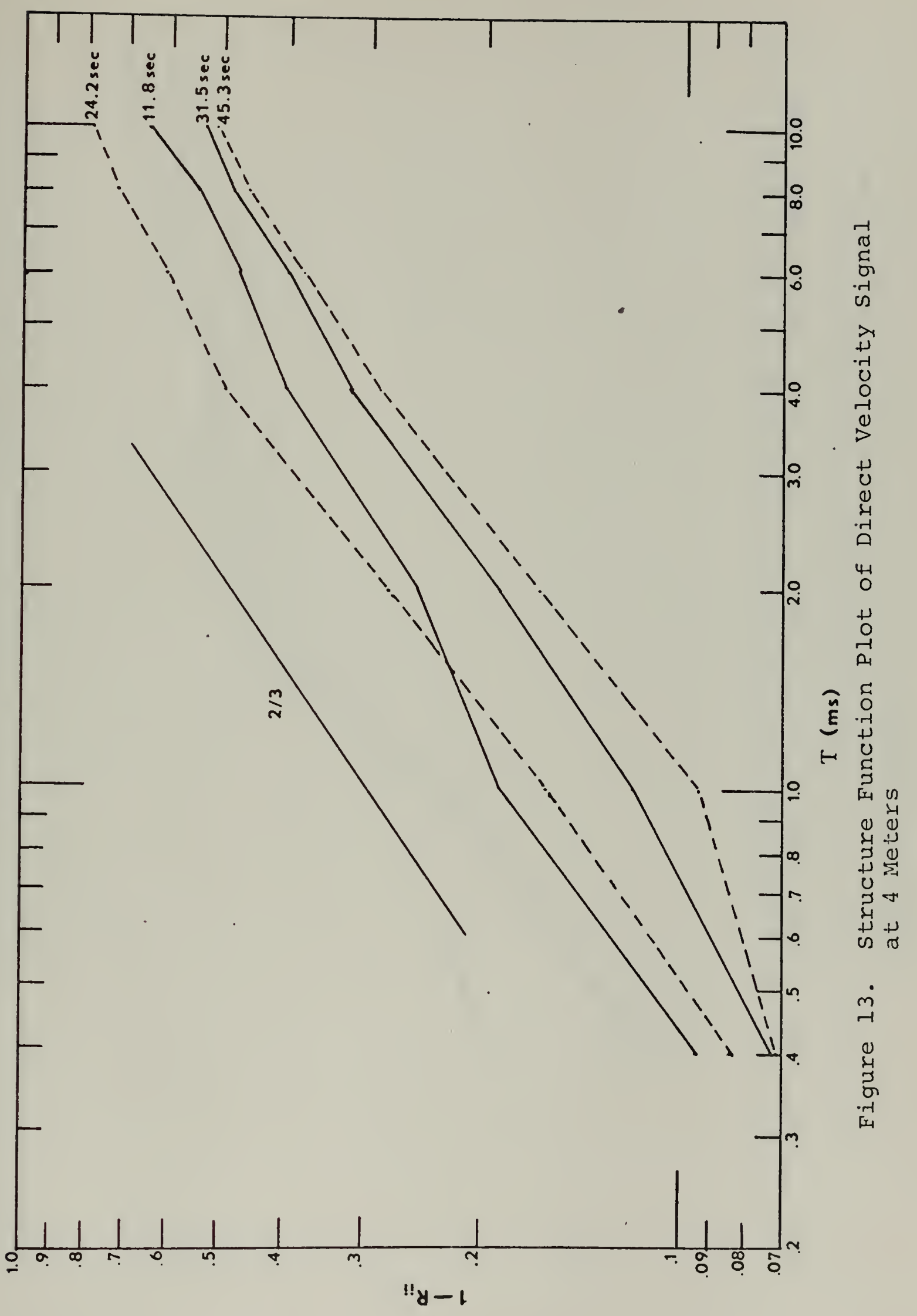





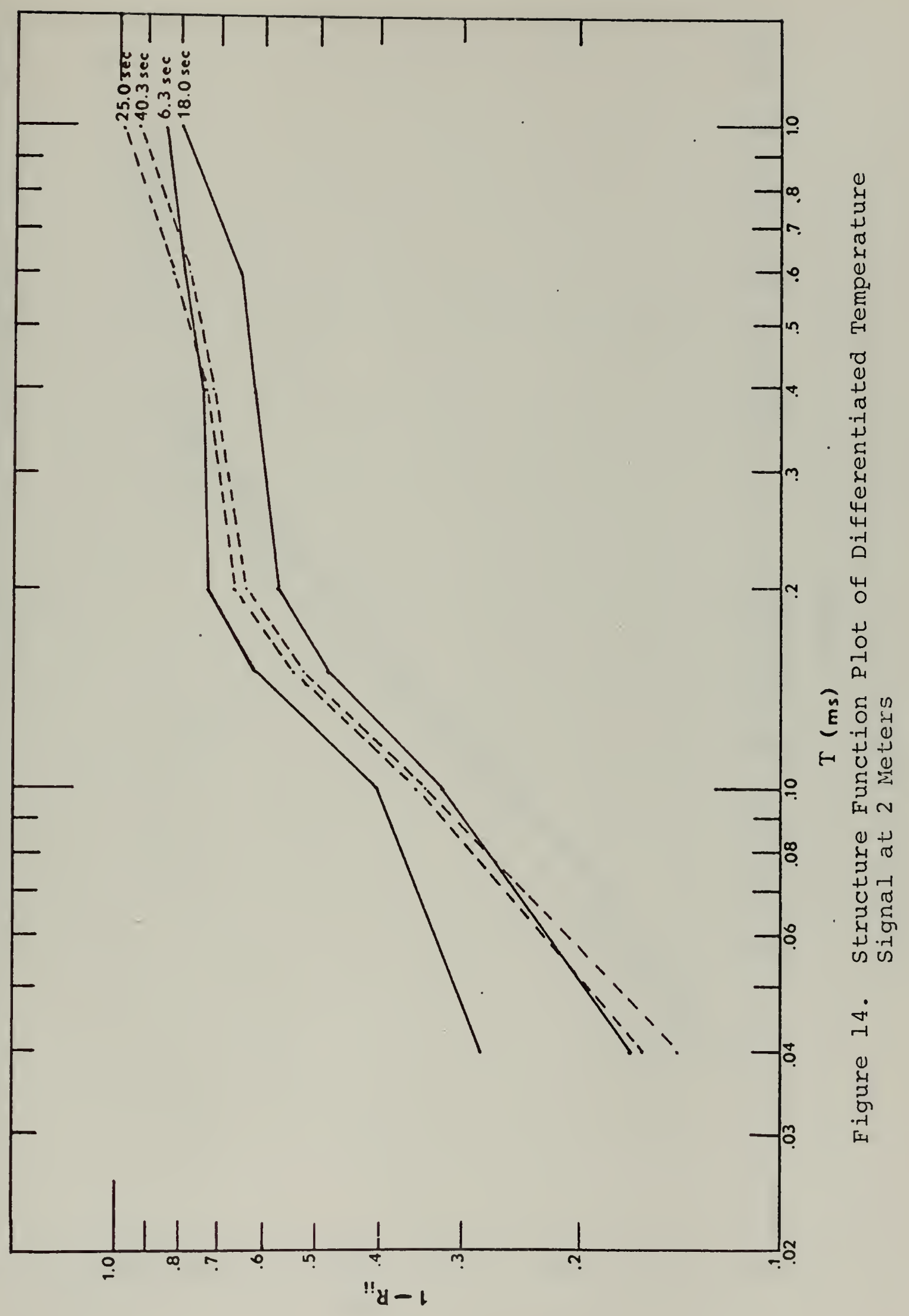





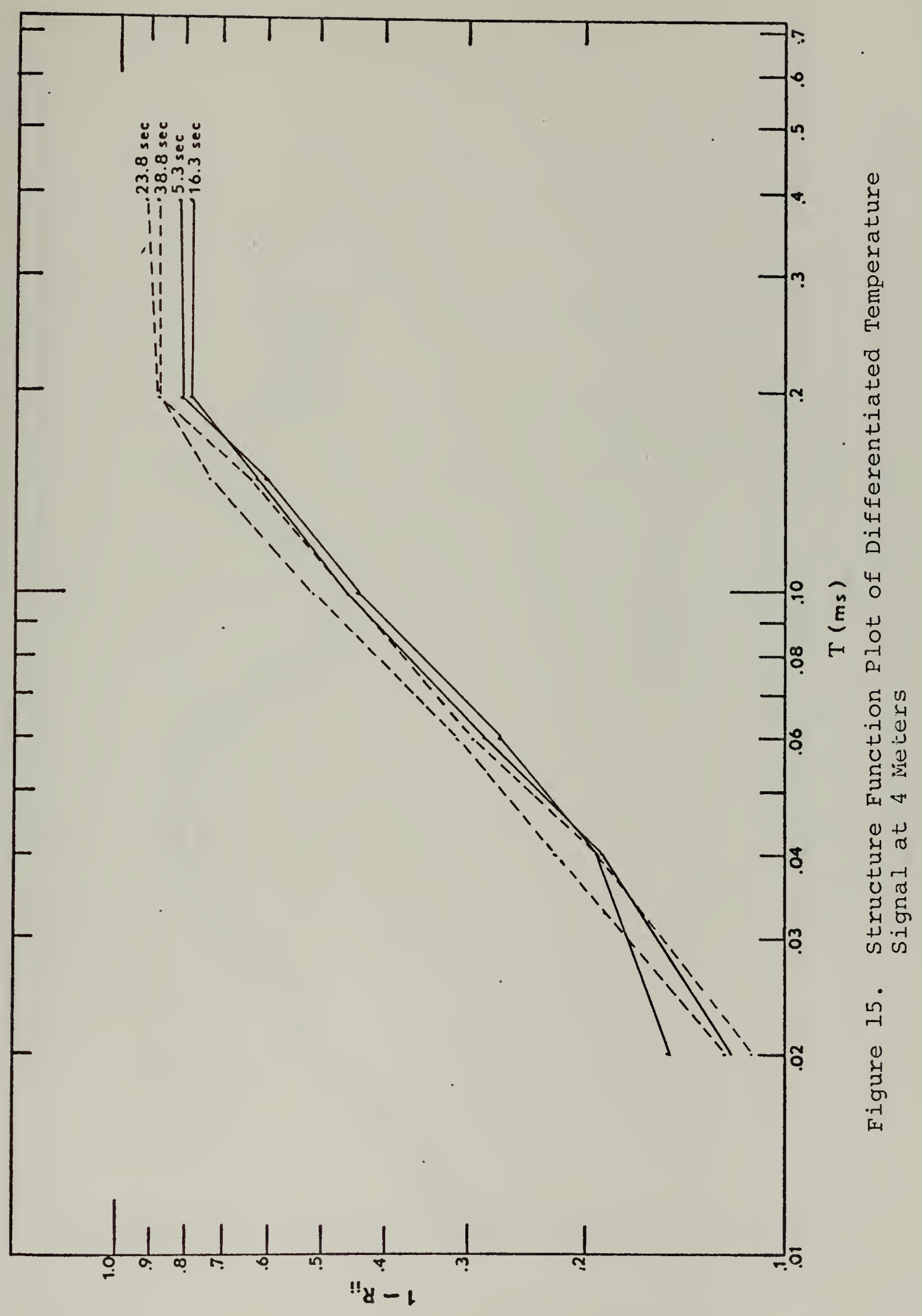





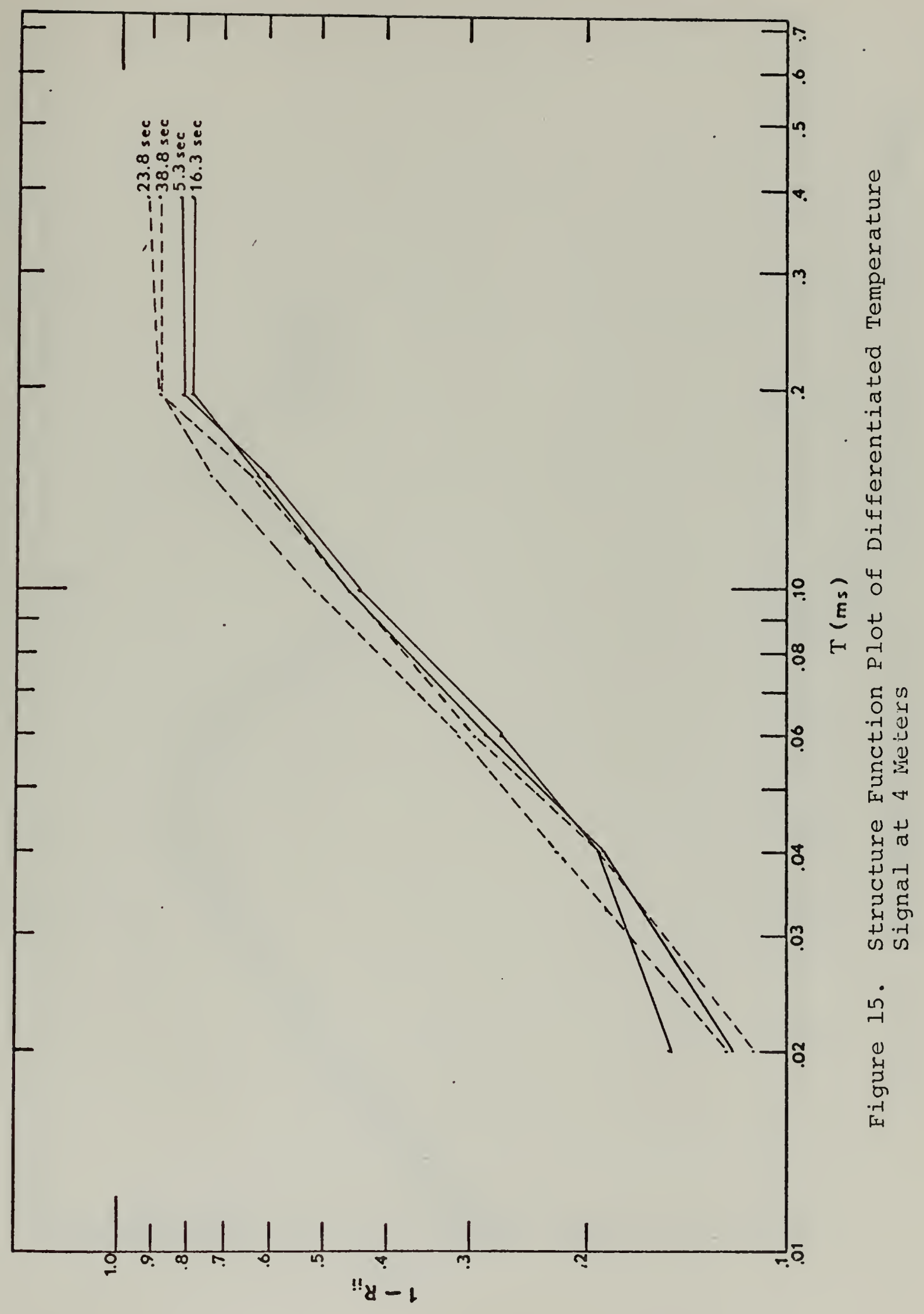





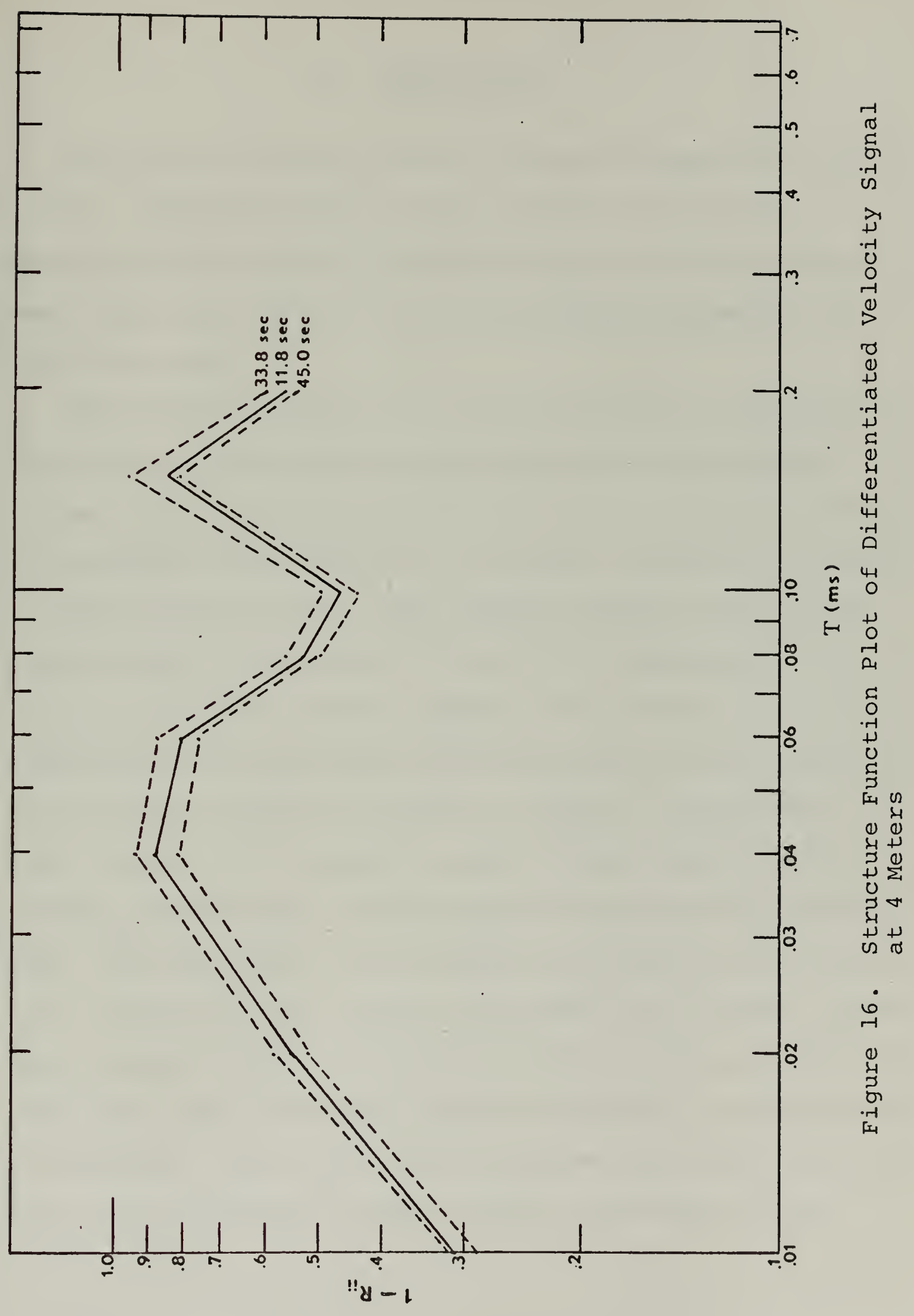





\section{CONCLUSIONS}

Analysis of the strip chart records of temperature fluctuations indicated that the data support Taylor's and Priestly's description of thermal plumes within a turbulent shear flow; and, as such, this study added information on these phenomena.

The data were consistent with predictions by similarity theory since both velocity and temperature fluctuations assumed a $+2 / 3$ power law behavior for the structure function in accordance with Kolmogorov's inertial subrange hypotheses.

The results of this study provide further support that the $+2 / 3$ power law behavior is valid for temperature fluctuations (Krechmer, 1952). Results of previous work in the atmospheric boundary layer have been primarily concerned with the structure function behavior of velocity fluctuations. At first glance, it is surprising that temperature as well as velocity fluctuations should exhibit consistent $+2 / 3$ slopes since the temperature traces showed the presence of intermittent active and quiet periods associated with thermal plumes. These plumes should be associated with anisotropic conditions since they imply vertically upward directional preference due to buoyancy. Thus, the isotropy deduced from the $+2 / 3$ behavior of the structure function and the anisotropy of the 

characteristic plumes appear to be a paradox. ${ }^{1}$ This apparent inconsistency can be explained by the fact that in this study only the very high frequency temperature fluctuations, which are independent of the features of the large scale flow, were examined. In order to see the difference in spectra or structure functions, the lower frequencies must be examined. The examination of these lower frequencies is one obvious future extension of this work.

The favorable design of the two sensors as indicated by the lack of correlation between velocity and temperature fluctuations at 4 meters elevation suggests that the two sensing systems used to measure the turbulence in this study are compatible and could continue to be used to make further measurements.

1 A $+2 / 3$ slope does not guarantee isotropy; isotropy is a sufficient condition for a $+2 / 3$ slope, but not a necessary condition. For examples, see Weiler and Burling (1967). 

APPENDIX A

\section{DIGITAL SPECTRAL ANALYSIS PROCEDURES}

A significant portion of the research in this study was an attempt to digitize the analog signals of temperature and velocity fluctuations, and then perform digital spectral analysis upon the data by means of a high speed digital computer. Despite the fact that various problems were encountered and only limited success resulted, it is worthwhile to discuss the procedures involved in this analysis since they could well be applicable to future studies of the relation between velocity and temperature fluctuations.

\section{A. ANALOG TO DIGITAL CONVERSION}

The analog to digital conversion was accomplished by means of a XDS 9300/CI 5000 Hybrid Computer system. The XDS 9300 is a digital computer manufactured by Xerox, Inc. with a 32,000 byte storage capacity, and the CI 5000 is a COMCOR analog computer with a 50-amplifier size rating. The temperature/velocity signal output of the Sangamo 3562 tape recorder was connected to a Krohn-Hite model 3340 low pass filter. The cut-off frequency settings were $2 \mathrm{kHz}$ for the undifferentiated signals and $4 \mathrm{kHz}$ for the differentiated signals. The signals were then fed to the analog computer patch panel. The signal was amplified in this patch panel to take advantage of the full dynamic range of the hybrid computer system. In 

subsequent troubleshooting, the patch panel was found to be a source of substantial noise. It is possible that this was one of the problems that precluded good results from this procedure.

From this patch panel, the signals were fed to the XDS 9300 digital computer. The digitized cutput of the XDS 9300 computer was then recorded on 7-track magnetic tape. Two channels of the analog tape recorder were digitized at one time. The procedures resulted in digital tape containing blocks of data 2048 words in size. Every other word in each block was a data sample from one channel. Thus each block of data contained 1024 words (data samples) of each channel. The sampling rate used for digitizing the undifferentiated signal was 2000 samples/second. The differentiated signal was sampled at a rate of 4000 samples/second. In the case of all signals, a 6-minute section of the 8-minute record was digitized. The procedure of digitizing two channels at one time was another possible source of error in this process. In future work, it is recommended that initially only one channel be digitized at a time in order to simplify troubleshooting in later stages of this procedure. Of course, when computing cross-spectra, it will be necessary to digitize two channels simultaneously.

For a more specific, detailed description of the general analog to digital conversion procedure used in this study, including programs, equipment settings, and further recommendations, see Jones (1971) 



\section{B. DIGITAL DATA PROCESSING}

The digital data processing was performed on an IBM $360 / 67$ computer. This system contains a core space of 762,000 bytes. Supporting equipment includes two compilers, two CALCOMP plotters, two printers, and twenty remote units. Digital tapes created by the hybrid computer system were written in 7-track form (octal representation). However the IBM $360 / 67$ system normally operates in 9-track form (hexadecimal representation). Therefore all data derived from the analog to digital conversion had to be converted to a 9-track format prior to analysis by the IBM 360/67. Standard subroutines existed for this conversion, but required some modifications as explained in Jones (1971). The output of this conversion was the digitized data on a 9-track tape. This process was another possible source of error. In troubleshooting this phase of the procedure, a program was written to plot the data of the 9-track tape. Numerous spikes not present in the raw analog data were found to be present in the 9-track data.

The next step in this procedure was the computation of the Fourier coefficients for the data. The program FTOR, described by Wilson, Boston, and Denner (1969), was used to accomplish this step. The output of the Fourier coefficients was recorded on another 9-track tape.

The final step in the digital data processing was the computation and plotting of the spectra. Two plotting programs, SCOR and FCPLOT, described by Wilson et. al. (1969), 

The digital data processing was performed on an IBM $360 / 67$ computer. This system contains a core space of 762,000 bytes. Supporting equipment includes two compilers, two CALCOMP plotters, two printers, and twenty remote units. Digital tapes created by the hybrid computer system were written in 7-track form (octal representation). However the IBM $360 / 67$ system normally operates in 9-track form (hexadecimal representation). Therefore all data derived from the analog to digital conversion had to be converted to a 9 -track format prior to analysis by the IBM $360 / 67$. Standard subroutines existed for this conversion, but required some modifications as explained in Jones (1971). The output of this conversion was the digitized data on a 9-track tape. This process was another possible source of error. In troubleshooting this phase of the procedure, a program was written to plot the data of the 9-track tape. Numerous spikes not present in the raw analog data were found to be present in the 9-track data.

The next step in this procedure was the computation of the Fourier coefficients for the data. The program FTOR, described by Wilson, Boston, and Denner (1969), was used to accomplish this step. The output of the Fourier coefficients was recorded on another 9-track tape.

The final step in the digital data processing was the computation and plotting of the spectra. Two plotting programs, SCOR and FCPLOT, described by Wilson et. al. (1969), 

read the output tape of the FTOR program and plotted various spectra. The SCOR program provided a plotted output of power spectra and cross spectra, and the FCPLOT program produced printer and ink drawings of amplitudes of Fourier coefficients. Both programs processed a single reel of digital tape (1368 blocks of 2048 words each) in less than 10 minutes computing time. In this study the SCOR program output of spectra and cross spectra for all reasured temperature and velocity fluctuations exhibited little relation to known power spectra behavior for such signals. The FTOR, SCOR, and FCPLOT programs have been used successfully in the past by Wilson, et. al. (1969) in analyzing such data. This leads to the belief that the problems encountered and general lack of results in this study were probably generated in either the analog to digital conversion or the 7-track to 9-track tape conversion processes.

Detailed information on the FTOR, SCOR, and FCPLOT programs can be found in Wilson, et. al. (1969). Specific details of the application of these programs to temperature and velocity fluctuations in the atmospheric boundary layer are described at length by Jones (1971). 



\section{BIBLIOGRAPHY}

Batchelor, G. K. 1953. The Theory of Homogeneous Turbulence. The University Press, Cambridge, England, $197 \mathrm{p}$.

Boston, N. E. J. 1970. An Investigation of High Wave Number Temperature and Velocity spectra in Air. Ph.D. Thesis, University of British Columbia, Jancouver, B.C., 125 p.

Dobson, F. W. 1969. Observations of Normal Pressure on Wind-generated Sea Waves. Ph.D. Thesis, University of British Coiumbia, Vancouver, B.C., 240 p.

Grant, H. L.; Stewart, R. W. ; and Moilliet, A. 1962. "Turbulence Spectra from a Tidal Channel." J. Fluid Mech., v. 12 , Part 2, p. 241-263.

Jones, R. D. 1971. Time Series Analysis of Analog Data by Analog and Digital Data Processing Methods at the Naval postgraduate School. M.S. Thesis, Naval Postgraduate School, Monterey, California, $70 \mathrm{p}$.

Kolmogorov; A. N. 1941. "The Local structure of Turbulence in Incompressible Viscous Fluid for Very Large Reynolds Numbers." Doklady ANSSSR, v. 30, p. 301-305.

Krechmer, S. I. 1952. "Investigation of the Micropulsations of the Temperature Field in the Atmosphere." Doklady ANSSSR, v. 84, p. 55-58.

Pond, S.: Stewart, R. W. ; and Burling, R. W. 1963. "Turbulence Spectra in the Wind Over Waves." J.Atmosph. Sci., v. 20 , p. 319-324.

Priestly, C. H. B. 1959. Turbulent Transfer in the Lower Atmosphere. The University of Chicago Press, Chicago., $130 \mathrm{p}$.

Strohbehn, J. W. 1968. "Line-of-Sight Wave Propagation Through the Turbulent Atmosphere." Proceedings of the IEEE, v. 56 , p. $1301-1318$.

Taylor, R. J. 1958. "Thermal Structures in the Lower Layers of the Atmosphere." Austral. J. Phys., V. 11, p. 168-176.

Webb, E. K. 1965. "Aerial Microclimate." Meteorological Monographs, v. 6, p. 27-58. 

Weiler, H. S. and Burling, R. W. 1967. "Direct Measurements of Stress and Spectra of Turbulence in the Boundary Layer over the Sea." J. Atmosph. Sci., v. 24, p. 653-664.

Wilson, J. R.; Boston, N. E. J.; and Denner, W. W. 1969. Digital Analysis of Turbulence Data on the IBM $360 / 67$ at the Naval Postgraduate School. Tech. Rep. NPS58DW9071A, Naval Postgraduate School, Monterey, California, $79 \mathrm{p}$. 

. No. Copies

1. Defense Documentation Center Cameron Station

Alexandria, Virginia 22314

2. Library, Code 0212

Naval Postgraduate School

Monterey, California 93940

3. Department of Oceanography, Code 58

Naval Postgraduate School

Monterey, California 93940

4. Asst Professor N. E. J. Boston, Code $58 \mathrm{Bb}$

Department of Oceanography

Naval Postgraduate School

Monterey, California 93940

5. LCDR Thomas E. Gill, II, USN

608 Garfield Avenue

Rockford, Illinois 61103

6. Asst Professor K. L. Davidson, Code 51 Ds

Department of Meteorology

Naval Postgraduate School

Monterey, California 93940

7. Assoc Professor W. W. Denner, Code 58 Dw

Department of Oceanography

Naval Postgraduate School

Monterey, California 93940

8. Assoc Professor J. B. Wickham, Code 58 Wk Department of Oceanography Naval Postgraduate School Monterey, California 93940 

Unclassified

Security Classification

\section{DOCUMENT CONTROL DATA - R \& D}

(Serurity classification of tllte. body of abstract and indexing annotation must be entered when the overall report is classified) ORIGINATING ACTIVITY (COTpOrale Guthor)

Naval Postgraduate School

Monterey, California 93940

Unclassified

REPORT TITLE

ANALYSIS OF TEMPERATURE AND VELOCITY

FLUCTUATIONS IN THE ATMOSPHERIC BOUNDARY LAYER

4 OESCRIPTIVE NOTES (Type of report and, inclusive dales)

March 1971

3. AUTHORISI (First name, middlo initial, last namo)

Thomas Edward Gill, II

Lieutenant Commander, United States Navy

\begin{tabular}{|c|c|c|}
\hline $\begin{array}{l}\text { G. REPORTDATE } \\
\text { March } 1971\end{array}$ & $\begin{array}{l}\text { 7a. TOTAL NO. OF PAGES } \\
57\end{array}$ & $\begin{array}{c}7 b . \text { NO. OF REFS } \\
14\end{array}$ \\
\hline $\begin{array}{l}\text { B. CONTRACT OR GRANTNE. } \\
\text { b. PROJECTNO. }\end{array}$ & \multicolumn{2}{|c|}{ QA. ORIGINATOR'S REPORT NUMBER(S) } \\
\hline $\begin{array}{l}\text { c. } \\
\text { d. }\end{array}$ & $\begin{array}{l}\text { Ob. OTHER REPORT NO(S) } \\
\text { (his ropori) }\end{array}$ & hor numbers that may bo asignod \\
\hline
\end{tabular}

Approved for public release; distribution unlimited.

11. SUPPLEMENTARY NOTES

\section{Naval Postgraduate School}

Monterey, California 93940

Measurements of high frequency temperature and velocity fluctuations were made in the atmospheric boundary layer. These data were analyzed using analog correlating techniques to obtain the structure function rather than spectral methods to obtain the spectral densities. The autocorrelation function of temperature fluctuations at 4 meters and 2 meters was computed as was the autocorrelation function of downstream velocity fluctuations at 4 meters. The cross-correlation function of temperature and downstream velocity fluctuations at 4 meters was also examined. These results supported the Kolmogorov ideas at high wave numbers. There is apparently very little correlation between downstream velocity fluctuations and temperature fluctuations. This indicates the independence of the two sensing systems and that temperature fluctuations are related primarily to vertical air movement rather than random fluctuations in the horizontal air flow. This aspect is further clarified by examining the temperature fluctuation records at two heights.

\section{DD FORM $\$ 473$ (PAGE 1 )}



Unclassified

Security Classification

\begin{tabular}{|l}
\hline \multicolumn{1}{|c|}{ Ker woros } \\
\hline Correlation Analysis \\
Temperature and Velocity Fluctuations \\
Atmospheric Boundary Layer \\
Structure Function \\
Inertial Sub-range \\
Turbulence
\end{tabular}





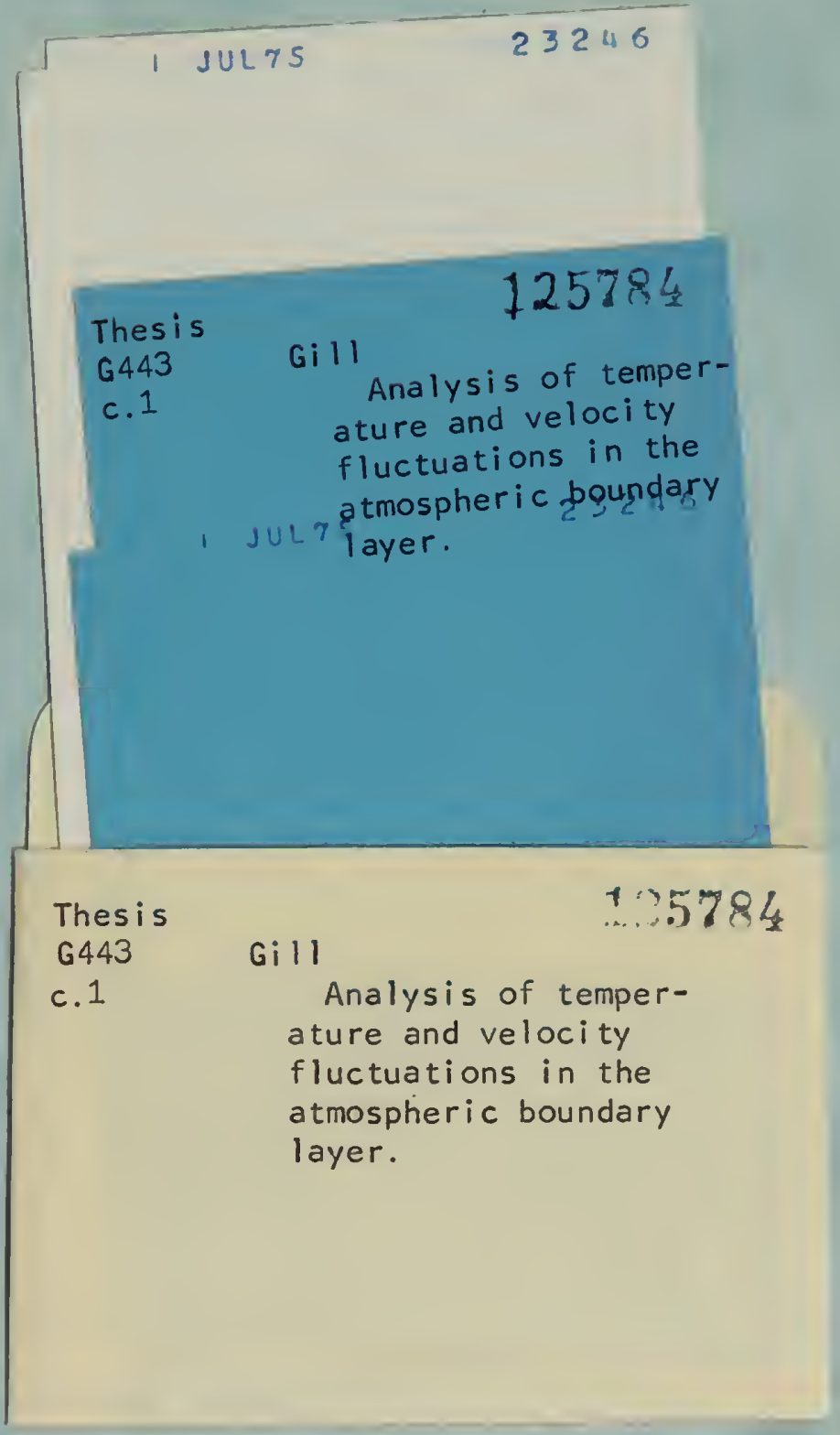


Analysis of temperature and velocity flu

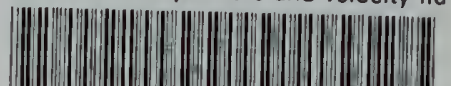
32768002029043
DUDLEY KNOX LIBRARY 